\title{
Multifield Coupling Mechanism of Unloading Deformation and Fracture of Composite Coal-Rock
}

\author{
Zhen Yang $\mathbb{D}$, Yan Li $\mathbb{D}^{D}$, Xin Li $\mathbb{D}$, Jiayu Zhuang $\mathbb{D}$, Hao Li $\mathbb{D}^{\mathbb{D}}$, Xue Wang $\mathbb{D}$, \\ and Yuning Wang $\mathbb{D}$ \\ Faculty of Electrical and Control Engineering, Liaoning Technical University, Huludao, Liaoning 125105, China \\ Correspondence should be addressed to Yan Li; 1llyyy65799@163.com
}

Received 11 May 2021; Accepted 23 June 2021; Published 5 July 2021

Academic Editor: Feng Du

Copyright ( $\odot 2021$ Zhen Yang et al. This is an open access article distributed under the Creative Commons Attribution License, which permits unrestricted use, distribution, and reproduction in any medium, provided the original work is properly cited.

\begin{abstract}
The deformation and fracture evolution of coal and rock under unloading are prone to sudden instability or dynamic damage. To solve the problem, this paper combines interdisciplinary theories such as damage mechanics and electromagnetic field theory. The mathematical model of multiphysics coupling during loading and unloading of composite coal-rock is deduced. In addition, numerical simulations along with experimental verification are carried out to study multi-physical field variation and coupling mechanisms. The composite coal-rock deforms and ruptures under unloading, and the brittle failure of the rock body becomes more sudden when the confining pressure is unloaded. Macroscopically, many microcracks are generated and expanded during the loading and unloading of composite coal-rock. Microscopically, the internal old molecular chains are broken to form new molecular chains by the force. Simulation results show that, during the loading and unloading process, the three physical fields of the composite coal-rock all change regularly. During the unloading of coal and rock, there is a transition period in which the temperature increases sharply and reaches the maximum. Then, the temperature decreases due to the gradual decrease of its bearing capacity. Besides, the electromagnetic field is strongest on the surface of the coal body, and its propagation in the air decays exponentially. There are small fluctuations that appear at the junction of the coal body and the air. The experimental results show that the internal infrared radiation temperature of the composite coal-rock decreases during the initial stage of loading and unloading due to the discharge of internal gas. In the first stage of "loading and unloading," it increases with the increase in stress, and the temperature suddenly increases in a short time after unloading. The electromagnetic radiation fluctuates in small amplitudes at the initial stage. When the stress is about to reach the peak, the electromagnetic radiation intensity increases and reaches the peak suddenly. Then, the coal-rock ruptures, the stress decreases, and the electromagnetic radiation weakens. The experiment and simulation results are consistent. The multiphysics coupling model is used to study the characteristics of coal and rock unloading under complex conditions, providing a theoretical basis and new method for the prediction and forecast of coal and rock mining dynamic disasters.
\end{abstract}

\section{Introduction}

With the gradual increase of the depth of coal mining in China, the mechanical problems in coal mining have become a research hotspot. In coal mining, affected by factors such as stopping and blasting, coal and rock will encounter complex mechanical processes of loading and unloading. The threeaxis loading and unloading process is closer to the actual mining process. During the mining process, multiple physical fields inside the coal and rock bodies are coupled and affect each other [1-3]. Lu et al. [4] established a rock stress-temperature numerical coupling model and studied the relationship between stress and temperature in the state of rock thermal damage. Reference [5] investigated the brittle failure pattern of coal-rock composite materials under uniaxial compression by laboratory tests and numerical simulations. Reference [6] established a coupling mathematical model of electromagnetic, heat, and mass transfer in the process of coal microwave heating, which can be used to deduce the coupling relationship between the electromagnetic field and temperature field of coal-rock. Ding et al. [7] summarized the failure process and characteristics of coal 
under different loading paths. They found that the loading path changed the manner of energy accelerate-release. There was more plastic strain generation in coal under cyclic loading than that under grade loading. The former was more likely to cause greater damage and failure. The strength of coal under cyclic loading is generally lower than that under grade loading, and an energy conversion mechanical model of stress, damage, and deformation was developed which explained the effect of the loading path. Yang et al. [8-10] studied electromagnetism, electric charge, and temperature changes of composite coal-rock under uniaxial loading, as well as the mechanical-electrical coupling and the mechanical-thermal-electrical coupling of the model. The coupled mathematical model between stress, temperature, and charge was derived.

To effectively predict dynamic disasters, scholars at home and abroad have carried out related studies from the perspectives of stress, electromagnetism, and temperature. Wang et al. [11] studied the charge time-frequency domain signal law of coal under various types of damage and refined the damage characteristics of coal samples. The stress characteristics and mechanical properties were studied and analyzed in reference [12], and the similarities and differences of composite coal mass with soft and hard coal mass in deformation and failure characteristics were compared. Moreover, the mechanical properties and deformation and failure laws of the composite coal mass under unidirectional loading were investigated. Reference [13] studies the mechanism of crack initiation, the damage characteristics, and the propagation law of high-voltage pulse hydraulic fracturing coal to evaluate the fracturing effect of coal-rock mass. To explore the acoustic emission and damage characteristics of rocks under different confining pressure unloading rates, $\mathrm{Li}$ [14] carried out rock $\mathrm{AE}$ test and deformation damage research of coal and rock under different unloading rates. In reference [15], the propagation law of ultrasonic signals in coal under different loading conditions was studied, and the ultrasonic testing system for deformation and failure of coal and rock was developed through cyclic loading and unloading. Zhang and Wang [16] studied the change characteristics of the electromagnetic signal of coal under impact load. Ai et al. [17] studied the relationship between the electromagnetic field and the crack change during coal rupture under uniaxial compression. The infrared radiation evolution law of damaged fracture surface of composite coal-rock is studied to realize noncontact prediction of coal and rock dynamic disaster [18]. The temporal and spatial evolution of infrared radiation information of unloading damage of composite coal-rock is revealed by considering the surface damage characteristics, three-dimensional infrared radiation field, and simulation software results. Yao et al. [19] studied active heat insulation roadway in high temperature mines. The ANSYS numerical simulation method is used for sensitivity analysis of the heat insulation layer with different thermal conductivity and thickness, as well as the surrounding rock with different thermal conductivity and temperature on a heat-adjusting zone radius, surrounding the rock temperature field and wall temperature. The results show that the heat-adjusting zone radius will entirely be in the right power index relationship to the ventilation time. Decrease in thermal conductivity and increase in thickness of insulation layer can effectively reduce the disturbance of airflow on the surrounding rock temperature, hence, beneficial for decreasing wall temperature. Lai et al. [20] found that the time-domain evolution of infrared radiation in the fracture process of fractured coal and rock is divided into four stages: Tave's calm, small fluctuations, rapid increase, and rapid decrease, which accurately describe the infrared radiation law of coal under uniaxial loading and unloading. Zhang et al. [21] monitored the change of infrared radiation temperature field of roadway surrounding rock by infrared radiation technology. This verified that the radiation temperature field had a good corresponding relationship with the failure characteristics of roadways. Wang and $\mathrm{Hu}$ [22] analyzed the characteristics and control factors of the temperature field of coal and rock mass in a deep mine. The interaction mechanism between seepage field and temperature field was also studied. The control characteristics of thermal physical properties of rock mass and geometric parameters of a fracture network on a temperature field were numerically simulated. The purpose of Du and Wang [23] is to improve the understanding of the outburst-rockburst coupling dynamic disasters mechanism. $\mathrm{Du}$ et al. [24] observed the uniaxial loading process of coal samples by infrared thermal imaging technology and strain monitoring technology. The response characteristics of surface average infrared radiation temperature (AIRT) and infrared thermal image in each stage of coal sample damage evolution were analyzed. The infrared radiation response mechanism in the evolution process of coal damage was revealed. According to Du et al. [25], conventional triaxial compression (CTC) tests were conducted on the gas-bearing coal, gas-bearing coal-mudstone combination, and gasbearing coal-sandstone combination using the RLW-500G triaxial experimental system.

Based on the above research results, relevant scholars have carried out research on stress characteristics, unloading fracture, and multifield coupling of coal and rock. However, there are few studies on the thermal-mechanical coupling mechanism of anisotropic coal and rock masses, and the research on thermal infrared radiation under the condition of triaxial unloading of composite coal-rock is not thorough enough. Pan et al. [26] applied the self-developed charge collection device to carry out gas seepage and charge induction tests for unloading confining pressure in gas-containing coal and rock. The results show that the gas seepage characteristics and charge induction law are closely related to the deformation and damage process of coal and rock during the unloading process of confining pressure. To research the evolution of energy stored in the composite coal-rock structure and coal fragments burst characteristics, lateral pressure unloading numerical tests of composite coalrock models with different Young's modulus were carried by PFC2D software in reference [27]. Reference [28] established the coal-rock composite models with different inclined angles by using particle flow code, and the impact instability characteristics after unloading were analyzed. In reference [29], a series of triaxial tests were conducted on gas- 
containing coal-sandstone combination samples under two types of unloading conditions. One is unloading confining pressure tests (UCPs), the other is unloading confining pressure-reloading axial stress tests (UCP-RAS).

To sum up, the crack evolution law of coal-rock combination under unloading conditions is less researched. There are few reports on the variation law of electromagnetic radiation, stress, and infrared radiation signals of composite coal-rock under loading and unloading conditions. And, there is no report on the analysis of unloading fracture mechanism from the perspective of multi-physical field coupling. Moreover, many dynamic disaster events of coalrock mining show that the occurrence of the events is accompanied by different degrees of precursor information, such as the variation of stress and strain, magnetic field, temperature, acoustic emission, and so on. By monitoring the changing trend and outlier of the signals, the risk of rock burst can be effectively forewarned. So, effective control measures can be taken in time to reduce the casualties and equipment damage caused by rock burst. For this reason, the change laws of composite coal-rock under loading and unloading are studied in this paper based on rock mechanics, thermodynamics, and damage mechanics. And, evolution laws of stress field, infrared radiation temperature field, and the electromagnetic field of composite coal-rock under the loading and unloading conditions are deeply studied, as well as the relationship among them. Through multiphysical field simulation and experiment, the prelude change law of composite coal-rock failure and fracture is obtained, which has important theoretical significance and engineering application prospect for coal-rock mining dynamic disaster prediction and prediction.

\section{Materials and Methods}

2.1. Multifield Coupling Mathematical Model of Composite Coal-Rock Unloading. The composite coal-rock deforms and fractures under unloading, the brittle failure characteristics of the rock mass under the condition of unloading confining pressure are obvious, and the failure is more sudden. Macroscopically, after many microcracks are generated in the coal and rock body under the initial stress state, the cracks extend and eventually rupture. Due to the thermal effect of the coal body, the temperature of the coal body changes and finally breaks. From a microscopic point of view, coal and rock are composed of atoms and electrons. Lauen [30] found that the crack propagation of coal and rock is the process of molecular bond fracture of its microstructure. The appearance of cracks is the phenomenon of dislocation and leakage between molecules and atoms. The extension and rupture of cracks are the result of the rupture of chemical bonds between molecules. The old molecular chain breaks to form a new molecular chain and finally maintains a new balance. Energy is released during chain formation. Earlier research results [8-10] indicate that one of the main causes of infrared radiation is heat generation by friction between cracks, and one of the main causes of electromagnetic radiation is the variable-speed movement of electric charges. Under the multiphase coupling action of "water-mechanicheat" with different stress, water content and temperature, the infrared characteristics, and rules of coal-rock damage are also different [18]. When the stress field, temperature field, and electromagnetic field are coupled, the microelement body in the composite coal-rock is selected for research.

During the loading and unloading process, the three principal stresses of the composite coal-rock are all nonzero [31], which conforms to the generalized Hooke's law. The principal stress-strain formula of the generalized Hooke's law is as follows:

$$
\left\{\begin{array}{l}
\varepsilon_{x}=\frac{1}{E}\left[\sigma_{x}-\mu\left(\sigma_{y}+\sigma_{z}\right)\right], \\
\varepsilon_{y}=\frac{1}{E}\left[\sigma_{y}-\mu\left(\sigma_{x}+\sigma_{z}\right)\right], \\
\varepsilon_{z}=\frac{1}{E}\left[\sigma_{z}-\mu\left(\sigma_{x}+\sigma_{y}\right)\right] .
\end{array}\right.
$$

Among them, $\varepsilon_{i}(i=x, y, z)$ is the principal strain; $E$ is the elastic modulus; $\sigma_{i}(i=x, y, z)$ is the principal stress; $u$ is Poisson's ratio.

The shear strain formula of the generalized Hooke's law is as follows:

$$
\left\{\begin{array}{l}
\gamma_{x y}=\frac{1}{G} \tau_{x y}=\frac{2(1+\mu)}{E} \tau_{x y}, \\
\gamma_{y z}=\frac{1}{G} \tau_{y z}=\frac{2(1+\mu)}{E} \tau_{y z}, \\
\gamma_{z x}=\frac{1}{G} \tau_{z x}=\frac{2(1+\mu)}{E} \tau_{z x} .
\end{array}\right.
$$

Among them, $\gamma_{i i}(i i=x y, y z, z x)$ is the shear stress; $\tau_{i i}$ $(i i=x y, y z, z x)$ is the shear strain; and $G=E /(2(1+u))$ is the Lame constant.

Equations (1) and (2) together form the generalized Hooke's law, which expresses the stress-strain relationship of composite coal-rock under unloading conditions, but it requires two sets of formulas to form together, and the effective stress formula $[32,33]$ is quoted to express taking the interior elements of coal and rock mass as the research object; the magnitude of the three principal stresses in the loading-unloading process is not zero, which conforms to the generalized Hooke's law. On the whole, the relationship between the effective stress and strain of composite coal-rock is as follows: 


$$
\left\{\begin{array}{c}
\frac{\sigma_{x}^{*}=\sigma_{x} E \mathcal{E}}{\left[\sigma_{z}-\mu\left(\sigma_{x}+\sigma_{y}\right)\right]} \\
\frac{\sigma_{y}^{*}=\sigma_{y} E \mathcal{E}}{\left[\sigma_{z}-\mu\left(\sigma_{x}+\sigma_{y}\right)\right]} \\
\frac{\sigma_{z}^{*}=\sigma_{z} E \varepsilon}{\left[\sigma_{z}-\mu\left(\sigma_{x}+\sigma_{y}\right)\right]}
\end{array}\right.
$$

$\sigma_{i} *(i=x, y, z)$ is the effective stress of composite coalrock; $\varepsilon$ is the strain.

The friction and heat generation of composite coal under the action of stress causes its temperature to change [34], and the relationship between temperature change and strain is:

$$
\Delta T=\frac{T V}{C}\left(\sum \beta \varepsilon_{i}+\sum \beta \tau_{i i}\right)
$$

Among them, $T$ is the initial temperature of composite coal rock, ${ }^{\circ} \mathrm{C} ; \mathrm{V}$ is the coal rock volume, $\mathrm{m} 3 ; \mathrm{C}$ is the heat capacity of coal and rock under constant strain, and $\mathrm{J} / \mathrm{K}$; $\beta=(\partial \sigma \mathrm{i} / \partial \mathrm{T}) \mathcal{\varepsilon},(\mathrm{i}=\mathrm{x}, \mathrm{y}, \mathrm{z})$ or $(\partial \tau \mathrm{ii} / \partial \mathrm{T}) \mathcal{\varepsilon},(\mathrm{ii}=\mathrm{xy}, \mathrm{yz}, \mathrm{zx})$ is the thermal stress coefficient; $\varepsilon \mathrm{i}(\mathrm{i}=\mathrm{x}, \mathrm{y}, \mathrm{z})$ is the main strain of coal rock; $\tau \mathrm{ii}(\mathrm{ii}=\mathrm{xy}, \mathrm{yz}, \mathrm{zx})$ is the shear strain of coal rock.

According to previous studies [8-10] and reference [35], the intensity of electromagnetic radiation produced by coal and rock mainly depends on the amount of crack charge, crack propagation speed, and acceleration. Substituting equations (1)-(3) into equation (4), in the process of unloading and rupture of composite coal-rock, the coupled mathematical model of infrared radiation temperature field, stress field, and electromagnetic field is as follows:

$$
\begin{aligned}
\Delta T & =\frac{T V}{C}\left(\frac{(1-2 \mu)}{E}\left(\beta_{x} \sigma_{x}+\beta_{y} \sigma_{y}+\beta_{z} \sigma_{z}\right)+\frac{E}{2(1+\mu)}\left(\beta_{x y} \gamma_{x y}+\beta_{y z} \gamma_{y z}+\beta_{z x} \gamma_{z x}\right)\right) \\
\vec{E} & =\vec{E}_{1}+\vec{E}_{2} \\
& =\left(1-\frac{n^{2} v^{2}}{c_{0}^{2}}\right) \frac{e \vec{r}}{4 \pi \varepsilon^{\prime}\left[\left(1-\left(n^{2} v^{2} / c_{0}^{2}\right)\right) r^{2}+(n \vec{v} \cdot \vec{r})^{2}\right]^{(3 / 2)}}+\frac{n^{2} e}{4 \pi \varepsilon^{\prime} c_{0}^{2} r} \frac{\vec{n} \times\left[\left(\vec{n}-\left(n \vec{v} / c_{0}\right)\right) \times v^{\prime}\right]}{\left(1-\left(n \vec{v} \cdot \vec{n} / c_{0}\right)\right)^{3}}, \\
\vec{B} & =\vec{B}_{1}+\vec{B}_{2}=\frac{n^{2} \vec{v}}{c_{0}^{2}} \times \vec{E}_{1}+\frac{n}{c_{0} \vec{n}} \times \vec{E}_{2} \\
& =\left(1-\frac{n^{2} v^{2}}{c_{0}^{2}}\right) \frac{e n^{2} \vec{v} \times \vec{r}}{4 \pi \varepsilon c_{0}^{2}\left[\left(1-\left(n^{2} v^{2} / c_{0}^{2}\right)\right) r^{2}+(n \vec{v} \cdot \vec{r})^{2}\right]^{(3 / 2)}}+\frac{n^{3} e}{4 \pi \varepsilon c_{0}^{3} r} \frac{\left[\left(\vec{n}-\left(n \vec{v} / c_{0}\right)\right) \times \overrightarrow{v^{\prime}}\right]}{\left(1-\left(n \vec{v} \cdot \vec{n} / c_{0}\right)\right)^{3}}, \\
\vec{E} & =\left(a \sigma_{z}^{3}+b \sigma_{z}^{2}+c \sigma_{z}\right) e^{-\alpha r} e^{i(\omega t-\eta r)} \cdot
\end{aligned}
$$

Among them: $n$ is the refractive index of the coal and rock body medium; $C_{0}$ is the electromagnetic wave propagation speed in vacuum, $\mathrm{m} / \mathrm{s} ; e$ is the charge of the particle, $C ; \varepsilon$ is the absolute dielectric constant of the medium; $\vec{v}$ is the moving speed of the charged particle, $\mathrm{m} / \mathrm{s} ; r$ is the distance between the charged particle and the observation point, $\mathrm{m} ; \vec{n}, \vec{r}$ are the unit vectors in the direction; $\overrightarrow{v^{\prime}}$ is the acceleration of the charged particle, $\mathrm{m} / \mathrm{s}^{2} ; \sigma_{z}$ is the axial stress of the microelement body where the electromagnetic radiation source is located; $a, b, c$, and $d$ are the experimental constants, $\alpha$ is the attenuation coefficient, and $\eta$ is the phase constant.

\section{Coal and Rock Finite Element Modeling}

3.1. Model Establishment. A three-dimensional axisymmetric composite coal-rock model is established and simulated to study the distribution of the stress field, temperature field, and the electromagnetic field of coal and rock during loading and unloading. Establish a standard cylinder with a radius of $25 \mathrm{~mm}$ and a height of $100 \mathrm{~mm}$, which is divided into three parts of "rock-coal-rock"; the ratio is $1: 1: 1$, the solution domain is an air radius of $200 \mathrm{~mm}$, and the ambient temperature is $20^{\circ} \mathrm{C}$. When the pressure is $3 \mathrm{MPa}$, there are four kinds of cracks during rock 
and coal fracture, one of which is about $35^{\circ}-45^{\circ}$ from the horizontal plane. The fractured state is similar to the loading mode of the coal body with the exposed surface in the actual mine. The coal samples mined in the composite coal-rock unloading experiment in this paper are from Xinzhouyao Mine in Datong, Shanxi. A lot of experiments have been done in the early stage, which meets the regulation. Therefore, the cracks and the coal-rock interface were artificially set in the simulation, the temperature simulation is set at the interface between coal and rock such that friction and relative sliding can occur, and the angle of the main coal fracture $[36,37]$ is $38.66^{\circ}$. The three-dimensional model of composite coal is shown in Figure 1.

3.2. Model Solving. The physical parameters of the mechanical, thermal, and electromagnetic materials involved in the model solution are listed in Table 1 , and the model dimensions are given in Section 2.1.

To realize the mechanical-electric-thermal three-field coupling, the indirect coupling method is adopted for the model. The structural field is analyzed by the Mohr-Coulomb plastic model. Transient structural system transient structural and coupling unit PLANE 223 are used for thermal transient analysis. Ansys-Maxwell3D static magnetic field analysis is used in magnetic field analysis, and the medium in the solution domain is set to be air.

\section{Simulation Research}

4.1. Stress Field Analysis. To better study the relationship between the unloading fracture mechanics stage of coal-rock and its infrared radiation temperature, the stress change process must first be clarified. Under the action of external load, the internal stress field of the composite coal-rock presents an axisymmetric distribution. The shear stress of the effective stress component in the tangential direction distribution is the largest at the crack. The strength decreases along the tangential direction. The tensile stress at the coalrock boundary increases with the increase of the external load. The principal stress along the axial direction is the strongest in the coal body, and the stress intensity at the bottom of the rock mass is higher than that at the top of the rock mass.

Figure 2 shows the axial stress-time curve of coal and rock. After a full investigation and under the condition that the simulation results are not false, this paper selects the commonly used slow unloading confining pressure rate of $0.03 \mathrm{MPa} / \mathrm{s}$ and confining pressure value of $3 \mathrm{MPa}[38,39]$. The three-axis loading and unloading of composite coal are divided into five stages: $0-2 \mathrm{~s}$ is a three-dimensional stress loading stage. In this stage, axial compression and confining pressure begin to apply pressure to change the internal of the composite coal-rock. At this time, the original small cracks of coal and rock are compacted with the increase of stress. Similar to the compaction stage in uniaxial loading, this stage is short due to the limitation of the size of the coal, and rock model $2-3 \mathrm{~s}$ is the stage of stress-keeping pressure. The time of this stage is short, and the axial compression and

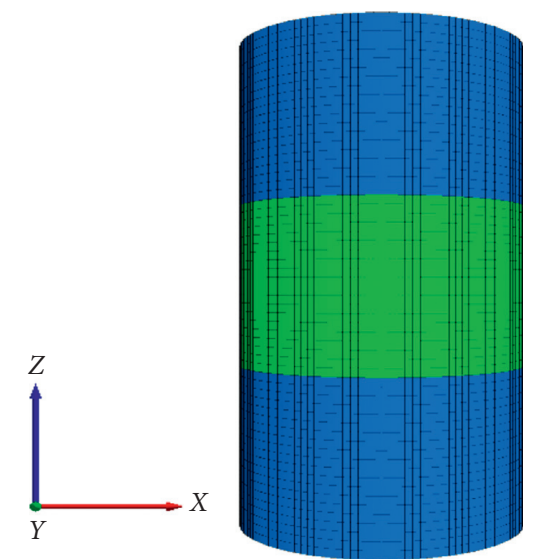

Figure 1: Three-dimensional model of composite coal-rock standard cylinder with a radius of $25 \mathrm{~mm}$ and a height of $100 \mathrm{~mm}$, which is divided into three parts of "rock-coal-rock," and the angle of the main coal fracture is $38.66^{\circ}$.

TABLE 1: The physical parameters of the mechanical, thermal, and electromagnetic materials involved in the model solution.

\begin{tabular}{|c|c|c|c|}
\hline Physical parameters & Coal & Rock & Air \\
\hline Density $\left(\mathrm{kg} / \mathrm{m}^{3}\right)$ & 1450 & 2400 & - \\
\hline Bulk modulus (GPa) & 1 & 4.5 & - \\
\hline Shear modulus (GPa) & 0.8 & 3 & - \\
\hline $\begin{array}{l}\text { Specific heat capacity }(\mathrm{J} / \\
(\mathrm{kg} \cdot \mathrm{k}))\end{array}$ & $1130 \mathrm{~J}$ & 916.9 & - \\
\hline $\begin{array}{l}\text { Thermal conductivity }(\mathrm{w} / \\
(\mathrm{m} \cdot \mathrm{k}))\end{array}$ & 1 & 2.8 & - \\
\hline $\begin{array}{l}\text { Thermal expansion } \\
\text { coefficient }\left({ }^{\circ} \mathrm{C}\right)\end{array}$ & $6.435 \times 10^{-6}$ & $6 \times 10^{-6}$ & - \\
\hline Poisson's ratio & 0.25 & 0.22 & - \\
\hline Resistivity $(\Omega \cdot \mathrm{m})$ & 550 & - & - \\
\hline Relative permeability $(\mathrm{m} / \mathrm{d})$ & $1 \times 10^{-6}$ & - & $1.256 \times 10^{-6}$ \\
\hline
\end{tabular}

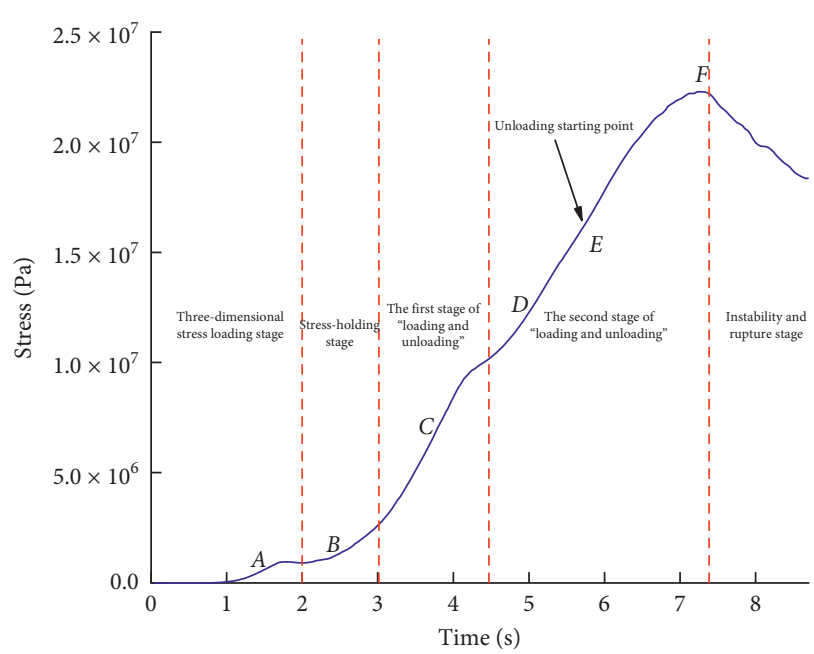

FIgURE 2: The axial stress-time curve of coal and rock. The confining pressure is set to $3 \mathrm{MPa}$ and the unloading rate is $0.03 \mathrm{MPa} / \mathrm{s}$. The three-axis loading and unloading of composite coal is divided into five stages. 
confining pressure resist each other. In this process, the changes of stress value are not obvious, the axial compression changes nonlinearly, and the deviatoric stress decreases. Finally, the axial compression overcomes the confining pressure and becomes dominant. The first stage of "loading-unloading" is 3-4.5 s, the curve is elastic, the stress increases linearly, the slope is large, the elastic modulus is large, and the composite coal is elastic. The second stage of "loading-unloading" is $4.5-7.5 \mathrm{~s}$, the mechanical trend of coal-rock first presents linear and then nonlinear, at this stage, the composite coal-rock gradually turns from elastic to plastic. After $7.5 \mathrm{~s}$, it is the instability and rupture stage. At point $E(t=5.8 \mathrm{~s})$, the confining pressure is unloaded at a certain rate until the maximum axial stress at point $F$ $(t=7.5 \mathrm{~s})$ is reached, the coal and rock are completely broken, and the curve drops rapidly, which showed strain softening.

Figure 3 is the cloud diagram of the composite coal-rock stress field during loading and unloading. Figures $3(\mathrm{a})-3(\mathrm{f})$ correspond to the six time points of $A B C D E F$ in Figure 2. Due to the approximate linearity between the two points, $A B C$ is the middle point of the three-dimensional stress loading stage, the stress-holding stage, and the first stage of "loading and unloading," respectively. $D$ is the middle point between the starting point of the second stage of "loading and unloading" and the starting point of unloading. $F$ is the unstable fracture point of composite coal-rock and also the highest point of stress. In the initial stage of loading and unloading, the change of the stress field of the rock mass is not obvious, and the stress of the coal body is greater because there are many pores in the coal body, and the strain of the coal body is larger than that of the rock body after compression. In the stress-holding stage, the confining pressure and axial pressure act on the composite coal-rock at the same time, and their effects are the same. The internal stress field of the whole composite coal-rock is changed in the shape of "O," due to the force on the upper and lower bottom and side of the composite coal-rock. At this stage, the axial pressure is gradually overcoming the confining pressure. In the first stage of "loading-unloading," the longitudinal stress field has a tendency of " $\mathrm{X}$ " shape [40]. At this time, the axial pressure has overcome the confining pressure and becomes the dominant composite coal-rock force. After entering the second stage of "loading-unloading," the composite coal-rock gradually transformed like a plastic state and began to have slight deformation. At this time, cracks and dislocation friction began to occur inside the coal body, and the stress on the rock body was gradually increasing. The internal microcracks are more obvious. At the point of failure, because the compressive strength of coal is less than that of rock, the coal body with many cracks was firstly unstable and ruptured, obvious cracks appeared in the rock body, and the whole stress field reached the maximum. In the whole process of loading and unloading, the stress field in the composite coal-rock shows an axisymmetric distribution.
4.2. Temperature Field Analysis. When the coal-rock is destroyed, its physical temperature will change by stress, which is the thermal-mechanical coupling effect [41].

Figure 4 shows the temperature program of composite coal-rock at different times; when the simulation time is $1.5 \mathrm{~s}, 2.5 \mathrm{~s}, 3.5 \mathrm{~s}, 5 \mathrm{~s}, 5.8 \mathrm{~s}$, and $7.5 \mathrm{~s}$, it corresponds to the six time points of $A B C D E F$ in Figure 2. In the initial stage of loading and unloading, there is no obvious high-temperature point inside the coal body. After entering the second stage of "loading-unloading," high-temperature points gradually appear, and there is a tendency to form cracks. Due to the different materials of composite coal-rock, the thermal conductivity of the coal body is lower than that of the rock body. Therefore, compared with rock bodies, the temperature distribution of the coal body is more uniform and the temperature gradient is larger [42].

The temperature detection is carried out at the interface of coal and rock and the interior of the coal body, as shown in Figure 4(f): $Y$ is the friction point of coal and rock, and $M$ is the high-temperature point inside the coal body. During the loading and unloading process, the magnified cloud diagrams of the change process of $Y$ and $M$ in the early, middle, and late stages are shown in Figures 5(a) and 5(b). It can be clearly seen from the figure that there is no hightemperature point in the coal body at the initial stage of loading and unloading, and the friction between coal and rock is not obvious; The temperature inside the coal body should be more uniform, and the tip temperature of the friction surface of coal and rock is the highest; Compared with the two, the average temperature inside the coal body is higher, which can be compared in Figure 6.

Figure 6 shows the temperature profile of the composite coal-rock during the loading and unloading stages. The changing trend of the friction surface of coal and rock, and the corresponding temperature-time curve at the hightemperature point of the coal body are consistent. In the initial stage of composite coal-rock loading and unloading, there are no cracks in the coal body during the two stages of three-dimensional stress loading and stress holding, and there is no obvious friction at the coal-rock junction. Entering the first stage of "loading and unloading," the temperature of the friction surface of coal and rock began to increase. In the second stage of "loading and unloading," high-temperature points appear inside the coal body where the temperature rise is larger than the friction surface of coal and rock. At this time, there are obvious microcracks inside the coal body, and the confining pressure begins to be unloaded at $5.8 \mathrm{~s}$; the reduction in the confining pressure caused the composite coal-rock to suddenly reduce its restraint, resulting in a large number of cracks and friction inside, and a sudden increase in temperature. The compressive strength of the coal body is smaller than the rock body, so the coal body ruptures more obviously, and the temperature rise is greater. At $6.1 \mathrm{~s}$, coal-rock friction and coal body high temperature reached the maximum values of $22.536^{\circ} \mathrm{C}$ and $32.16^{\circ} \mathrm{C}$, respectively, and then reached the 


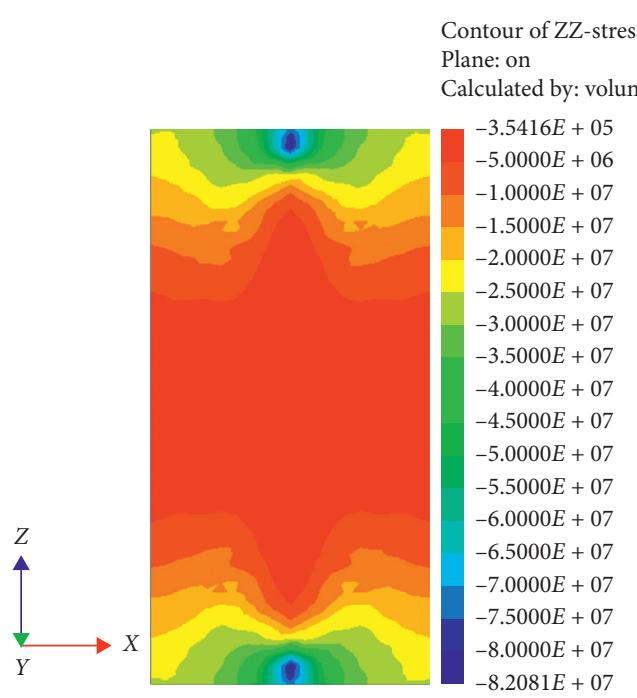

(a)

Contour of ZZ-stress Plane: on

Calculated by: volumetric averaging

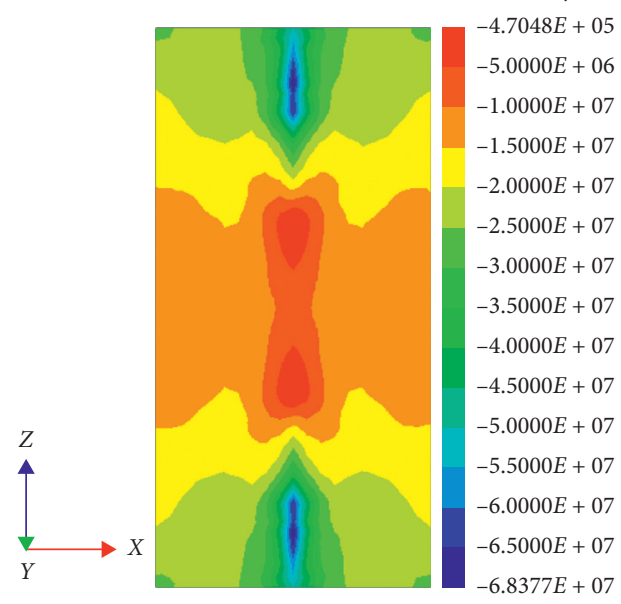

(c)

Contour of ZZ-stress

Plane: on

Calculated by: volumetric averaging

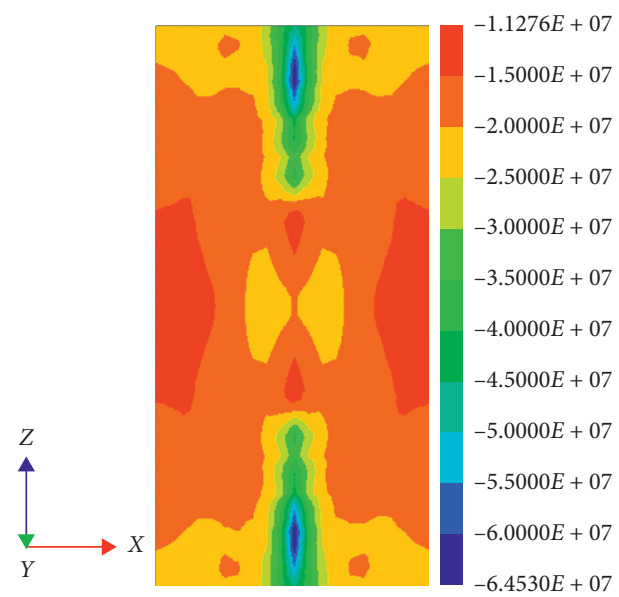

(e)

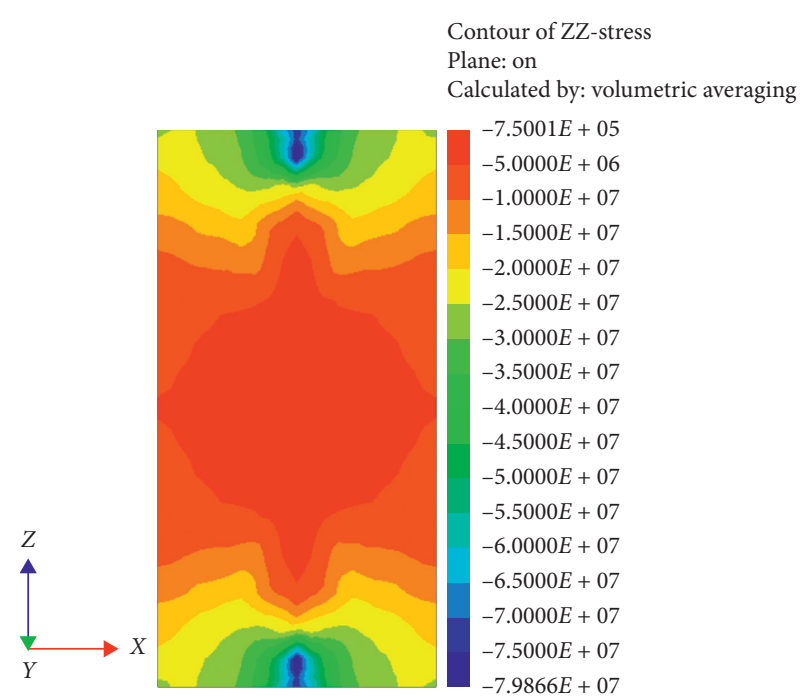

(b)

Contour of ZZ-stress

Plane: on

Calculated by: volumetric averaging

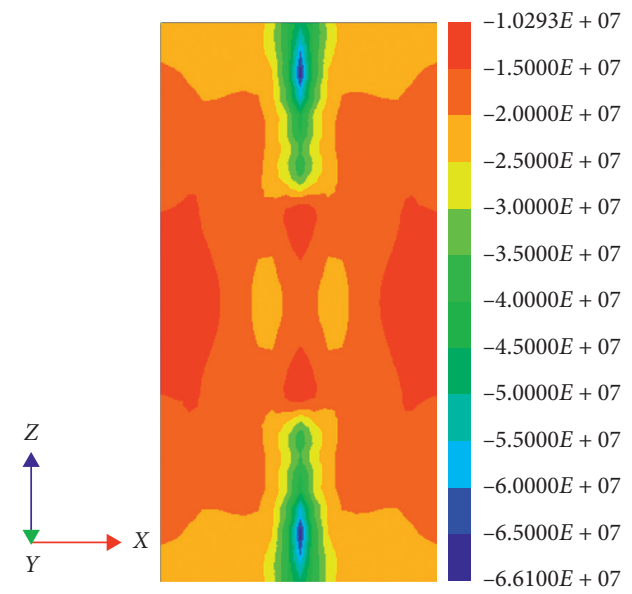

(d)

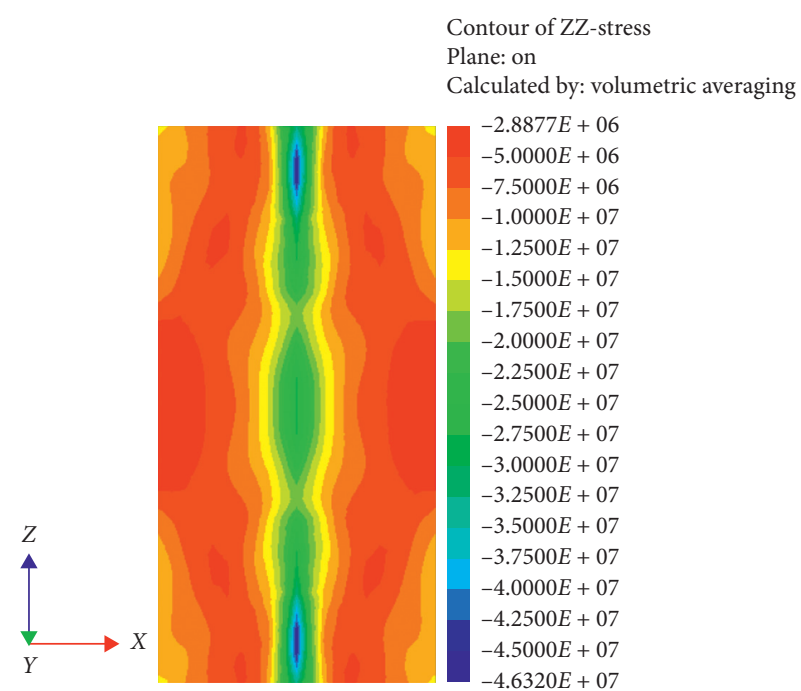

(f)

Figure 3: Stress field distribution of composite coal-rock in different stages. (a) $t=1.5 \mathrm{~s}$, (b) $t=2.5 \mathrm{~s}$, (c) $t=3.75 \mathrm{~s}$, (d) $t=5.15 \mathrm{~s}$, (e) $t=5.8 \mathrm{~s}$, and (f) $t=7.5 \mathrm{~s}$ correspond to the six time points of $A B C D E F$ in Figure 2. 


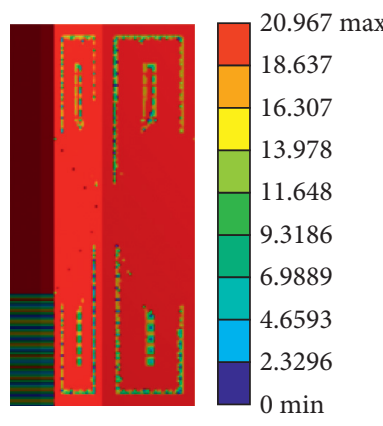

(a)

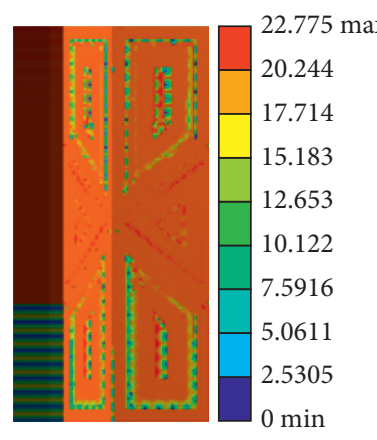

(d)

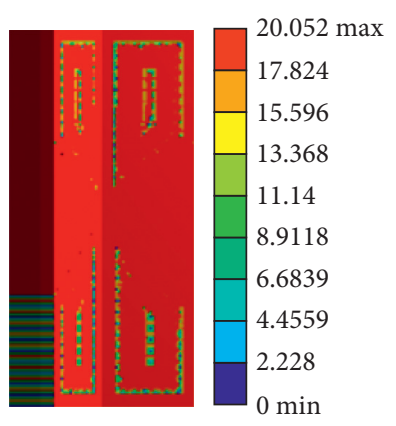

(b)

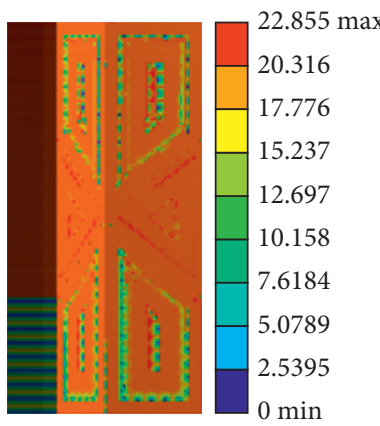

(e)



(c)

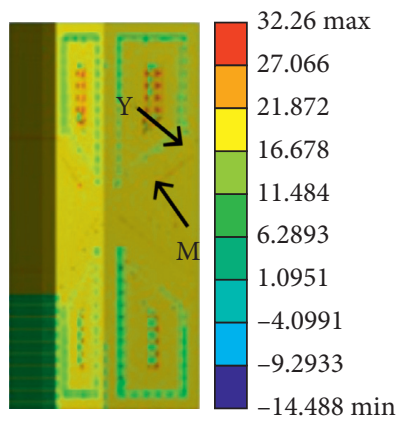

(f)

Figure 4: Temperature nephogram of composite coal-rock at different times; when the simulation time is $1.5 \mathrm{~s}, 2.5 \mathrm{~s}, 3.5 \mathrm{~s}, 5 \mathrm{~s}, 5.8 \mathrm{~s}$, and $7.5 \mathrm{~s}$, it corresponds to the six time points of $A B C D E F$ in Figure 2. (a) $t=1.5 \mathrm{~s}$, (b) $t=2.5 \mathrm{~s}$, (c) $t=3.75 \mathrm{~s}$, (d) $t=5.15 \mathrm{~s}$, (e) $t=5.8 \mathrm{~s}$, and (f) $t=7.5 \mathrm{~s}$.

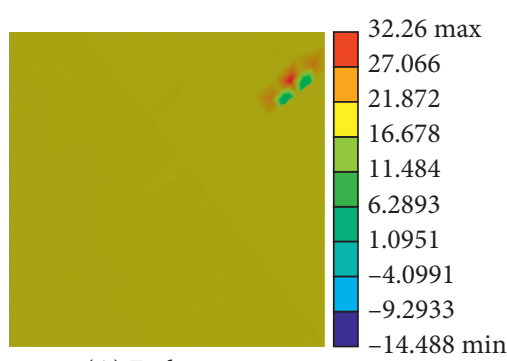

(A) Early stage

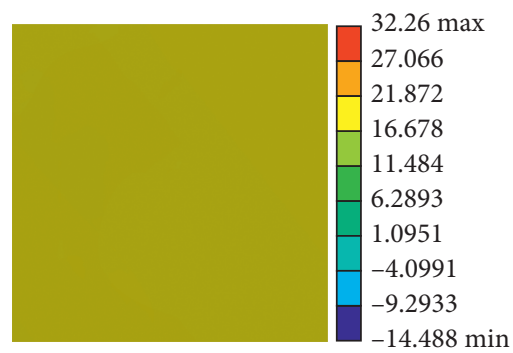

(A) Early stage

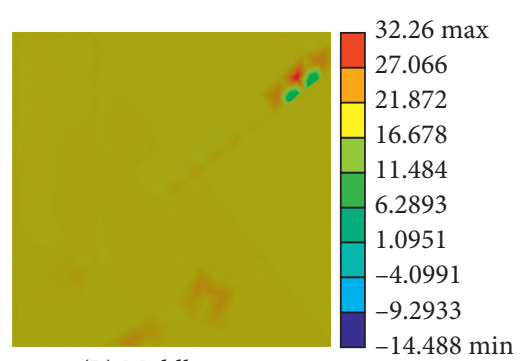

(B) Middle stage

(a)



(B) Middle stage

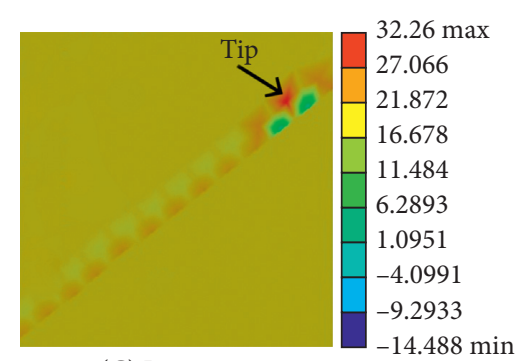

(C) Late stage

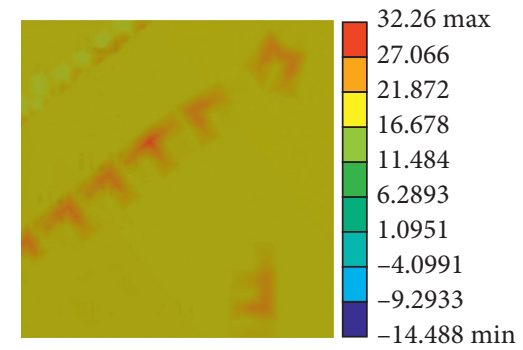

(C) Late stage

(b)

FIGURE 5: Coal-rock friction and high temperature point of coal temperature nephograms of friction, fracture amplification. (a) Coal-rock friction. (b) High temperature point of coal.

maximum stress at $7.5 \mathrm{~s}$, which resulted in an unstable fracture. The loading and unloading temperature curve takes the overall average temperature of the fracture in the composite coal-rock. Compared with the high-temperature point of the coal, there is a green low-temperature zone on the friction surface of the coal and rock as shown in Figure 5(a), so the overall average temperature is lower than the high-temperature point inside the coal. 


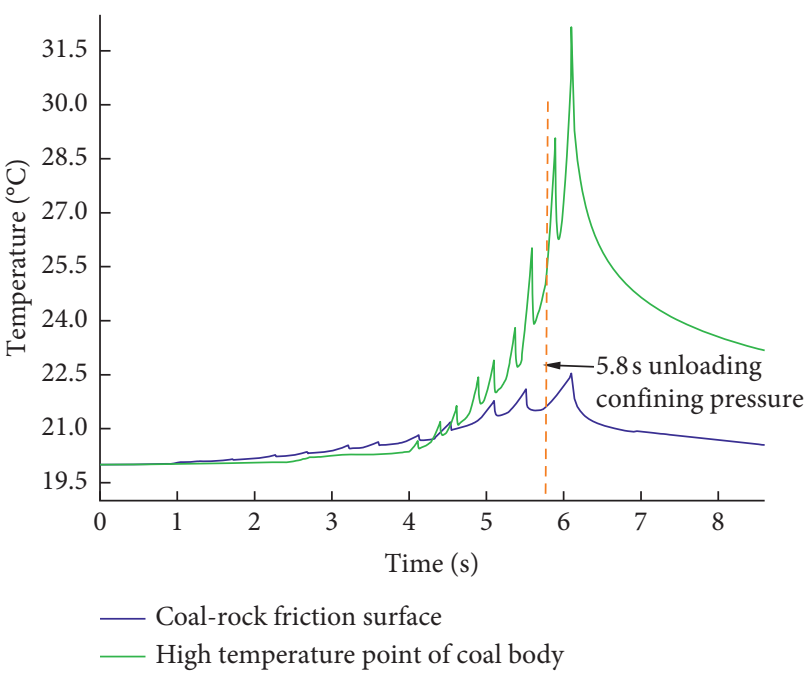

FIgURE 6: Temperature curve of composite coal-rock loading and unloading.

4.3. Electromagnetic Field Analysis. Electromagnetic radiation is produced by the variable motion of charged particles. The precondition of electromagnetic radiation is charge separation. All materials are composed of atoms and electrons, and the coal and rock mass does not show electromagnetic radiation phenomena without external disturbance. However, when subjected to external disturbance, some of the original bound charges in the coal and rock mass will become free charges, and the concentration and quantity of free charges will increase. At the same time, the uneven structure and anisotropy of the composite coalrock mass itself will occur. In this process, the transfer and movement produce electromagnetic radiation phenomenon.

In the process of loading and unloading the composite coal-rock, the coal and rock particles rub against each other to separate the electric charges, and the electric charges move at a variable speed to generate electromagnetic radiation. Figure 7 shows the magnetic field intensity generated by coal loading and unloading at different times corresponding to the six time points $A B C D E F$ in Figure 2. Observing the cloud map of magnetic field intensity, it is found that the magnetic field intensity inside the coal body gradually increases from the center to the outside, while it is gradually attenuated in the air. When $t=7.5 \mathrm{~s}$, the axial stress is the maximum, and the magnetic field intensity generated by the coal body reaches the maximum value of $10.82 \mu \mathrm{A} / \mathrm{m}$.

Figure 8 is a vector diagram of the electromagnetic field intensity. It can be seen more clearly that the direction of the magnetic field inside the coal body and the external vacuum is the same, and the intensity of the electromagnetic field spreads outward along the surface of the coal body and decays continuously.

Figure 9 is a graph of the propagation of the electromagnetic field intensity of the coal body. The six curves correspond to the six time points of $A B C D E F$ in Figure 2. Observing the propagation curve of the magnetic field intensity, it is found that the maximum value of the electromagnetic field intensity at any time is at the junction of the coal body and the propagation medium, $25 \mathrm{~mm}$ from the origin. Due to the movement and separation of electric charges inside the coal body, many electric charges accumulate on the surface of the coal body, resulting in low electromagnetic field intensity at the center of the coal body-the closer to the surface, the higher the electromagnetic field intensity. The electromagnetic intensity fluctuates slightly due to the change of the propagation medium at the junction of the coal body and air. Then, the electromagnetic field intensity decays from the inside to the outside when it propagates in the air, and the overall decline is exponential. In the initial stage of loading and unloading of composite coal-rock (point A and point B), the electric charge movement is weak, and the amplitude of electromagnetic field change is not obvious. After the first stage of "loading-unloading," the intensity and change range of the electromagnetic field increases significantly. The maximum electromagnetic field intensity values at the six moments are $0.35015 \mu \mathrm{A} / \mathrm{m}, \quad 0.7003 \mu \mathrm{A} / \mathrm{m}, \quad 5.261 \mu \mathrm{A} / \mathrm{m}, \quad 6.476 \mu \mathrm{A} / \mathrm{m}$, $7.567 \mu \mathrm{A} / \mathrm{m}$, and $10.82 \mu \mathrm{A} / \mathrm{m}$. When the propagation distance reaches $200 \mathrm{~mm}$, the electromagnetic intensity is $0.07675 \mu \mathrm{A} / \mathrm{m}, \quad 0.1535 \mu \mathrm{A} / \mathrm{m}, \quad 1.298 \mu \mathrm{A} / \mathrm{m}, \quad 1.487 \mu \mathrm{A} / \mathrm{m}$, $1.713 \mu \mathrm{A} / \mathrm{m}, 2.639 \mu \mathrm{A} / \mathrm{m}$.

4.4. Research on Multifield Coupling Mechanism of Composite Coal-Rock Unloading. The electromagnetic field and the temperature field are connected through the stress field, and the stress is applied to the composite coal-rock to change the movement state of the internal microelement body and break its original balance. In the process of breaking the chemical bonds of internal molecules, strain is generated and energy is released, so that the infrared radiation temperature changes, and the variable speed movement of the charges generated in the coal and rock fissures produces electromagnetic radiation, which causes changes in the electromagnetic field.

Figure 10 shows the relationship curve between electromagnetic field intensity, the overall average temperature of coal, rock, and stress. Among them, the intensity of the electromagnetic field has good consistency with the axial stress, and the electromagnetic radiation also changes correspondingly with the change of the stress. 0-2s: The composite coal-rock is in the three-dimensional stress loading stage, the stress increases slightly, the internal charge moves slowly, and the electromagnetic radiation starts to be active but not obvious. At this stage, the gas in the internal voids of the coal is discharged. This process consumes a part of the heat and causes the overall temperature to drop. 2-3 s: In the stress-holding stage, the axial pressure is overcoming the constraint of confining pressure, the internal stress field of the composite coal-rock is in a stable stage, and the corresponding electromagnetic radiation activity and temperature are relatively stable. $3-4.5 \mathrm{~s}$ : Entering the first stage of "loading and unloading," with the increase of stress, the internal charge of composite coal-rock begins to move under the influence of external force, the intensity of electromagnetic field increases, and affected by thermoelastic effect, the temperature curve of composite coal-rock begins to rise 




(a)

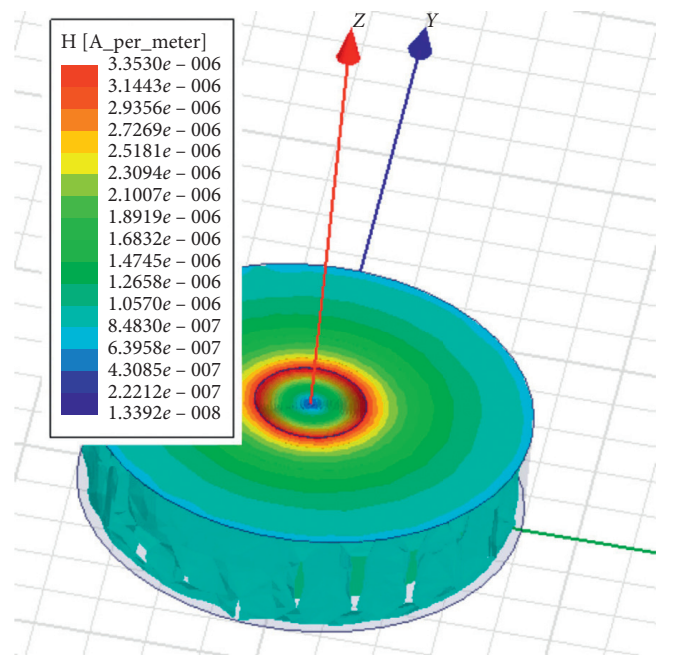

(c)

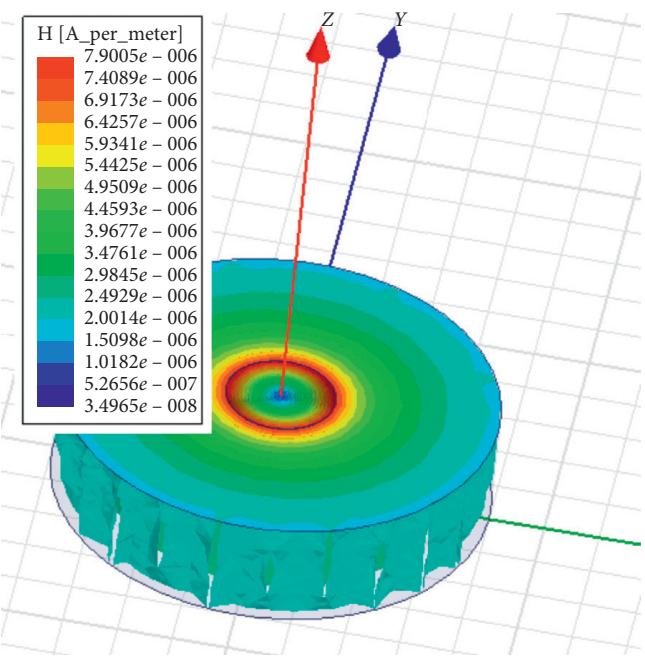

(e)

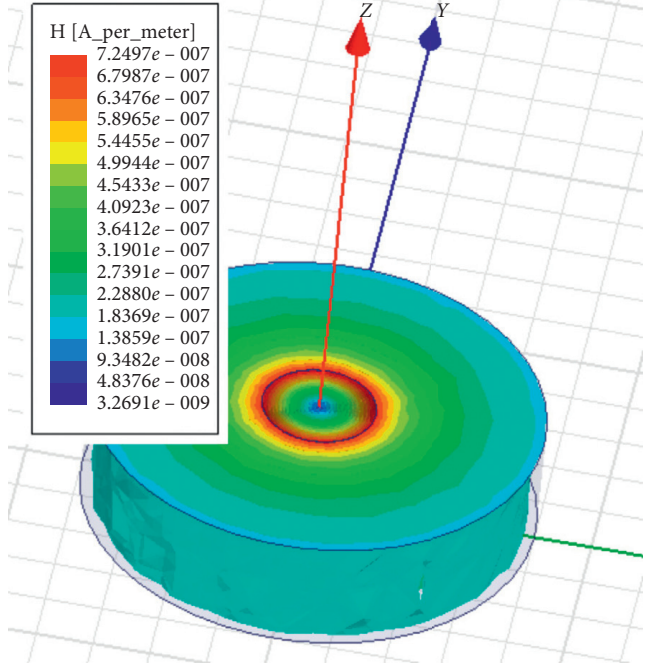

(b)

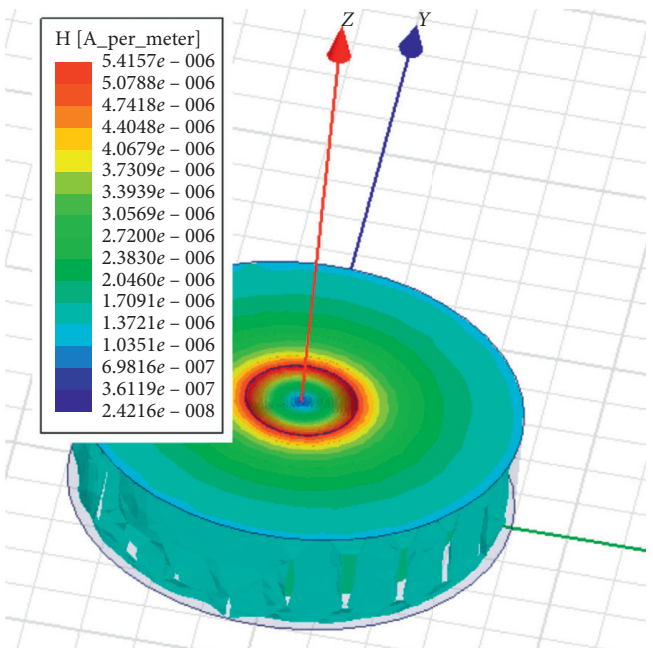

(d)

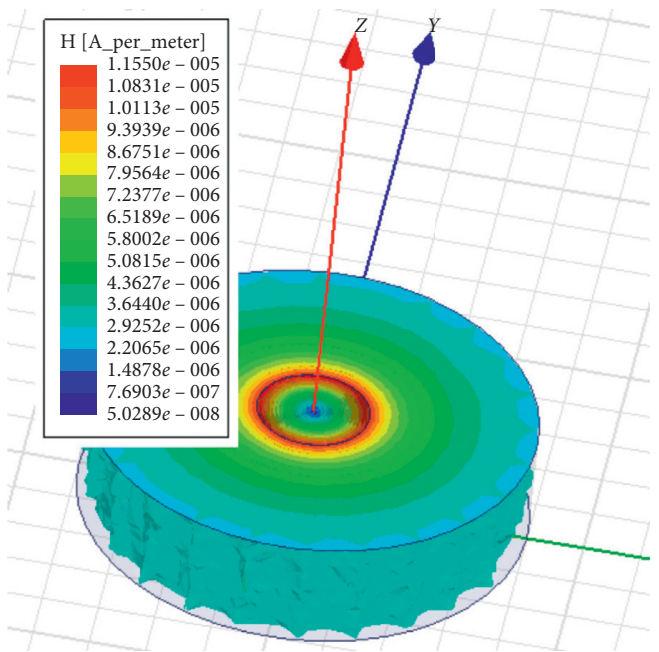

(f)

FIgURE 7: Magnetic field intensity generated by coal loading and unloading at different times corresponding to the six time points $A B C D E F$ in Figure 2. (a) $t=1.5 \mathrm{~s}$, (b) $t=2.5 \mathrm{~s}$, (c) $t=3.75 \mathrm{~s}$, (d) $t=5.15 \mathrm{~s}$, (e) $t=5.8 \mathrm{~s}$, and (f) $t=7.5 \mathrm{~s}$. 


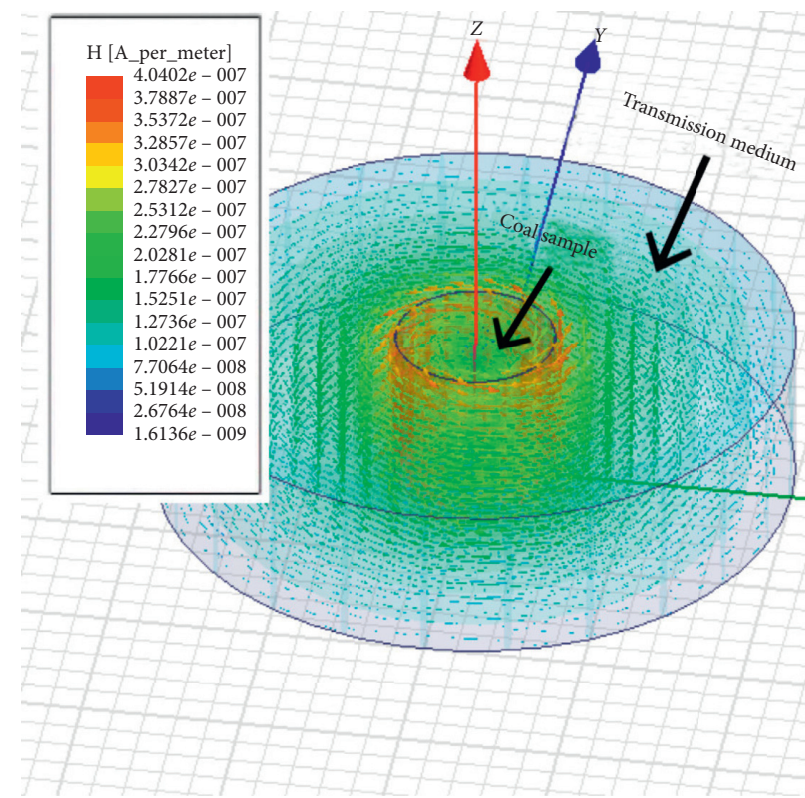

(a)

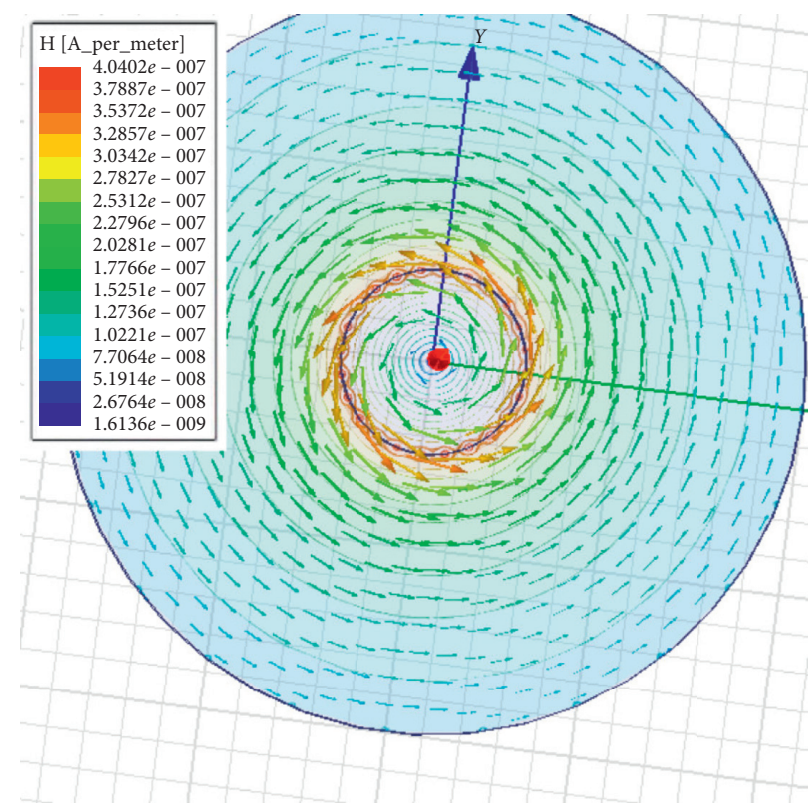

(b)

FiguRE 8: Vector diagram of magnetic field intensity, the direction of the magnetic field inside the coal body, and the external vacuum is in the same direction, and the intensity of the electromagnetic field spreads outward along the surface of the coal body and decays continuously.

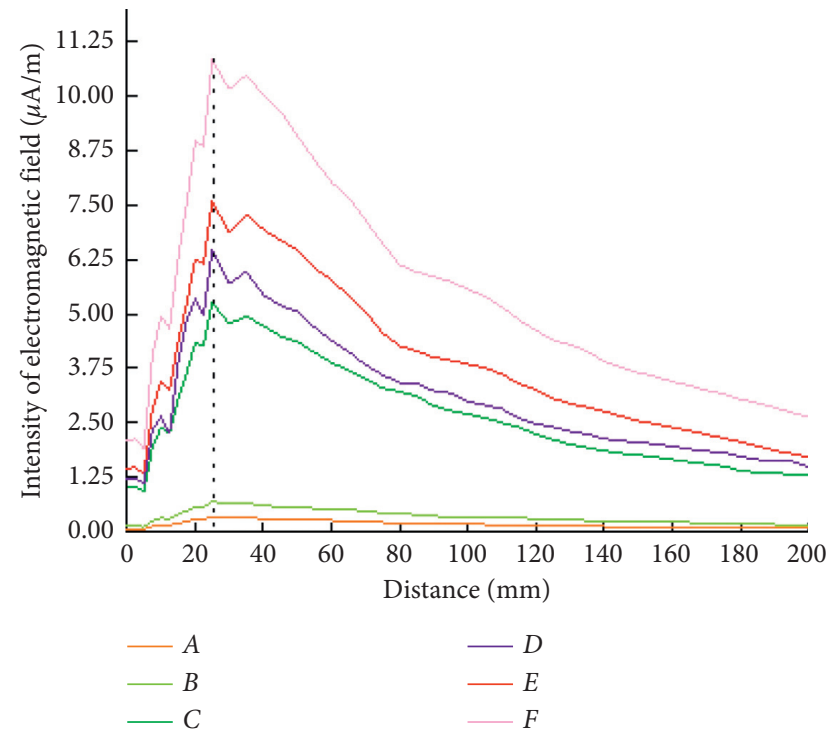

FIGURE 9: Electromagnetic field intensity propagation curve; the six curves correspond to the six time points of $A B C D E F$ in Figure 2.

and the temperature curve is approximately linear. 4.5 s-7.5 s: It is the second stage of "loading and unloading," and the confining pressure begins to be unloaded at a certain rate at $5.8 \mathrm{~s}$. The intensity of the electromagnetic field is related to the movement of the electric charge. Due to the increase of the axial pressure, the stress of the composite coal-rock is still increasing and the speed of the movement of the internal electric charge is accelerating. The decrease of the confining pressure does not affect the intensity of the electromagnetic field, and the intensity of the

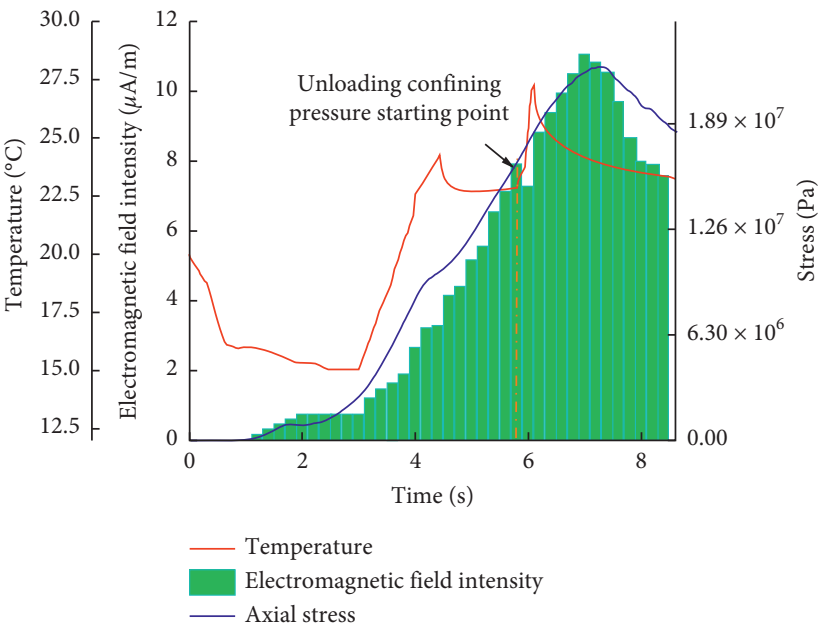

FIGURE 10: Relation curve of electromagnetic field strength, overall average temperature, and stress of composite coal-rock.

electromagnetic field continues to increase until it reaches the peak value at the same time as the stress. At this stage, the temperature has changed three times. Due to the external force at work, the coal and rock will undergo plastic deformation due to microcracking, heat is absorbed, and the temperature will drop; at $5.8 \mathrm{~s}$, the confining pressure begins to be relieved while the axial pressure continues to increase. Compared with the previous period, the internal microfracture of the composite coal-rock that suddenly reduced the confining pressure was intensified, resulting in a large number of cracks, which extended and expanded, and the sudden increase in heat reached the maximum value of 
$27.26^{\circ} \mathrm{C}$. This short and rapid heating stage is a transitional adaptation period for the composite coal-rock to unload the confining pressure. After the adaptation period, there have been a large number of microcracks inside the composite coal-rock. The deformation is more obvious than before, resulting in secondary expansion, consuming more heat, and reducing the temperature again.

The electromagnetic radiation of composite coal-rock mainly comes from the variable speed movement of electric charge. The stress-holding stage of internal crack is accelerated, and the temperature increases suddenly. The rate of unloading confining pressure is certain, and after adapting to the process of unloading confining pressure, the composite coal-rock returns to a relative equilibrium state and enters the secondary expansion, resulting in a decrease in temperature. Compared to the relationship between stress, electromagnetic radiation, and temperature of composite coal-rock, the process of unloading confining pressure has almost no effect on the changes of electromagnetic radiation, and temperature requires a short transitional adaptation period.

\section{Experimental Research}

Figure 11 shows a schematic diagram of the triaxial test equipment and field test. The experimental system is composed of a TAW-2000 microcomputer-controlled hightemperature rock triaxial testing machine, control cabinet, data collector, and computer. The press is a single axis feeding and pressing mode, and the maximum load is $300 \mathrm{kN}$. The electromagnetic radiation signal detection device is self-developed, which is composed of a broadband loop antenna, signal conditioning circuit, and data acquisition and processing circuit. The signal acquisition range of the antenna is $1 \mathrm{~Hz} \sim 1 \mathrm{MHz}$. The charge meter is independently developed with a charge voltage conversion ratio of 80-100 mV/PC. The coal and rock samples all come from deep coal seams in Xinzhouyao, Datong, Shanxi. To better simulate the actual situation of coal mining, the confining pressure and unloading rate designed in the experiment are larger than the conditions set by simulation, which not only ensures that it is more consistent with the actual situation but also can be compared with the simulation to analyze and study the results of composite coal-rock under the conditions of different confining pressure unloading rates. Cut the coal and rock samples in the laboratory, and cut the top sandstone, bottom sandstone, and coal samples at a height of $1: 1: 1$ into 6 cylindrical composite coal-rocks with a radius of $25 \mathrm{~mm}$ and a height of $100 \mathrm{~mm}$. The samples are divided into two groups: $0.05 \mathrm{MPa} / \mathrm{s}$ (numbered $a^{\#}, b^{\#}, c^{\#}$ ) and $0.2 \mathrm{MPa} / \mathrm{s}$ (numbered $d^{\#}, e^{\#}, f^{\#}$ ).

\section{Experiment Procedure}

(1) Seal the composite coal-rock samples with heatshrinkable tubes, and install strain sensors, infrared probes, and electromagnetic radiation probes. Put them into the pressure cylinder, push the pressure cylinder into the tester, open the oil valve to inject silicone oil, and close the oil valve when it is full.

(2) Turn on the power supply and apply three-dimensional stress $\sigma_{1}=\sigma_{2}=\sigma_{3}$ to $10 \mathrm{MPa}$ according to the water pressure condition.

(3) Keep the confining pressure constant; the axial pressure is loaded at a rate of $0.002 \mathrm{~mm} / \mathrm{s}$, until it reaches about $70 \%$ of the compressive strength under triaxial loading, and the confining pressure is released.

(4) Keep the axial pressure during the unloading process to continue loading and set the unloading rate to $0.05 \mathrm{M}$ and $0.2 \mathrm{MPa} / \mathrm{s}$, respectively.

(5) When the axial stress exceeds the peak stress, the sample will immediately stop unloading the confining pressure, keep the confining pressure constant, and continue to apply the axial stress until the stress curve no longer changes with the change of strain, and the test ends.

Figure 12 shows the experimental results of the samples numbered $a^{\#}, b^{\#}, c^{\#}, d^{\#}, e^{\#}$, and $f^{\#}$. During loading and unloading, the lithology changes. Because the compressive strength of the samples in the experiment is higher than that in the simulation model, the composite coal samples suffer through splitting failure, and the macroscopic fracture morphology of the samples changes from " $\mathrm{X}$ " deformation to inverted " $Y$ " shape. This shape is due to relatively high specimen strength, the end effect is more prominent, and the end is caused by the triaxial stress state due to the friction inhibition. The larger the "loading-unloading" rate, the more concentrated the failure is on a macro fracture surface, the failure mode changes from multi macro fracture to single macro fracture, and the overall crushing degree is reduced. The main reason is that when the velocity is small, the generation, expansion, and penetration of microcracks are more sufficient, and it is easier to form " $\mathrm{X}$ "-type fracture as described in the simulation, with a greater degree of fragmentation; However, when the rate is high, the crack in the sample cannot be fully expanded, and the macro fracture surface is formed along the weakest direction, which is the inverted " $Y$ " fracture in the experimental results. The crack angle is about $35^{\circ}-45^{\circ}$, and there is no obvious crack in the rock body.

Figures 13(a) and 13(b) show the electromagnetic radiation intensity, temperature, and stress curves of the specimens unloading confining pressure at the rate of 0.05 $\mathrm{MPa} / \mathrm{s}\left(\right.$ Sample $\mathrm{a}^{\#}$ ) and $0.2 \mathrm{MPa} / \mathrm{s}\left(\right.$ Sample $\mathrm{d}^{\#}$ ) at the same 10 $\mathrm{MPa}$ confining pressure, respectively. The composite coalrock is subjected to axial pressure and confining pressure at the same time, and the voids in the coal-rock are exhausted more quickly than uniaxial loading. 0-20 s: the time of the two stages of the three-dimensional stress loading and stressholding stage is extremely short, especially the stress-holding stage is only about $3 \mathrm{~s}$. In these two stages, the coal body is compressed, and the internal pores are closed, the electromagnetic radiation changes little, and the temperature decreases. In the first stage of "loading and unloading," the 


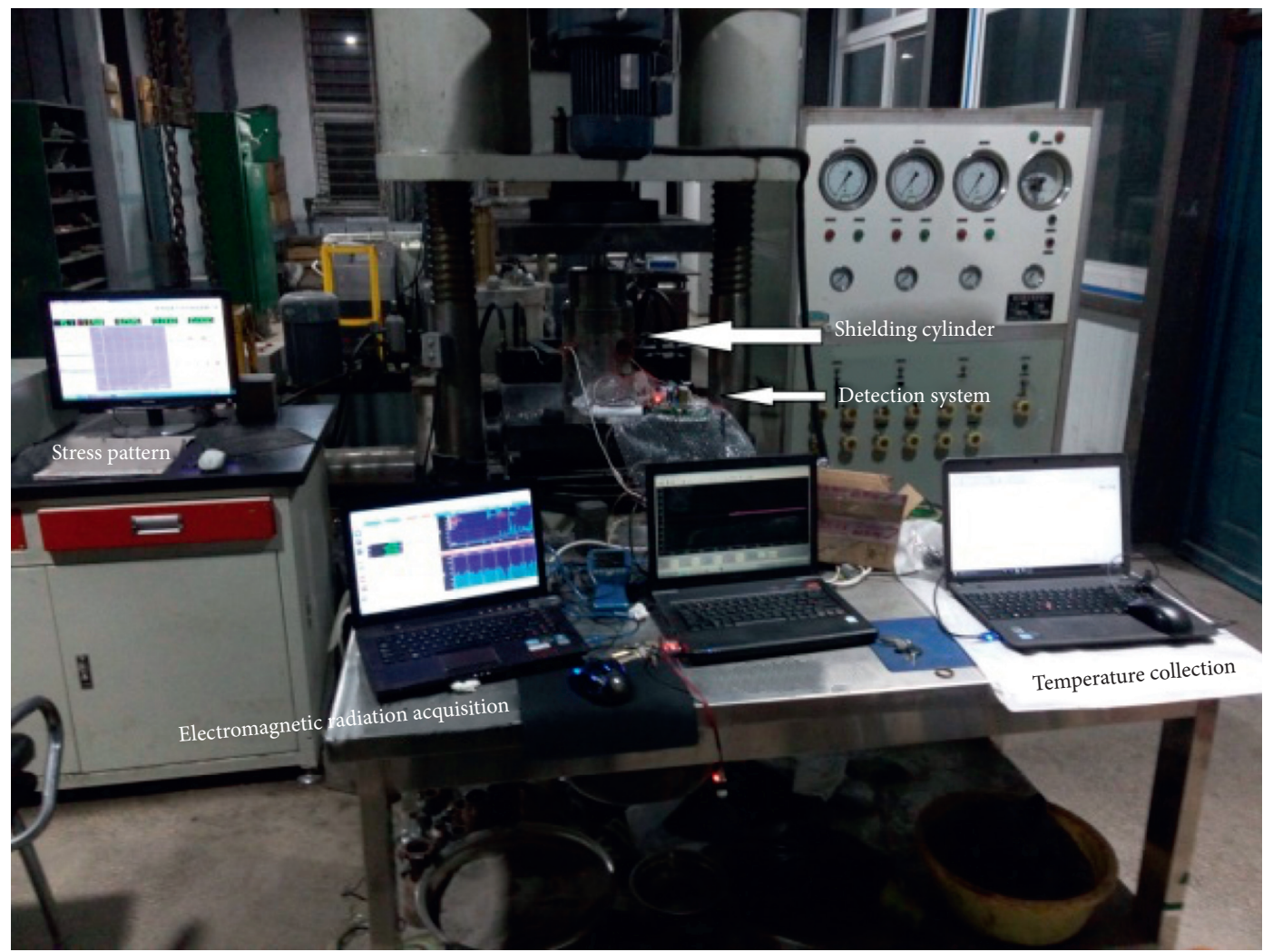

(a)

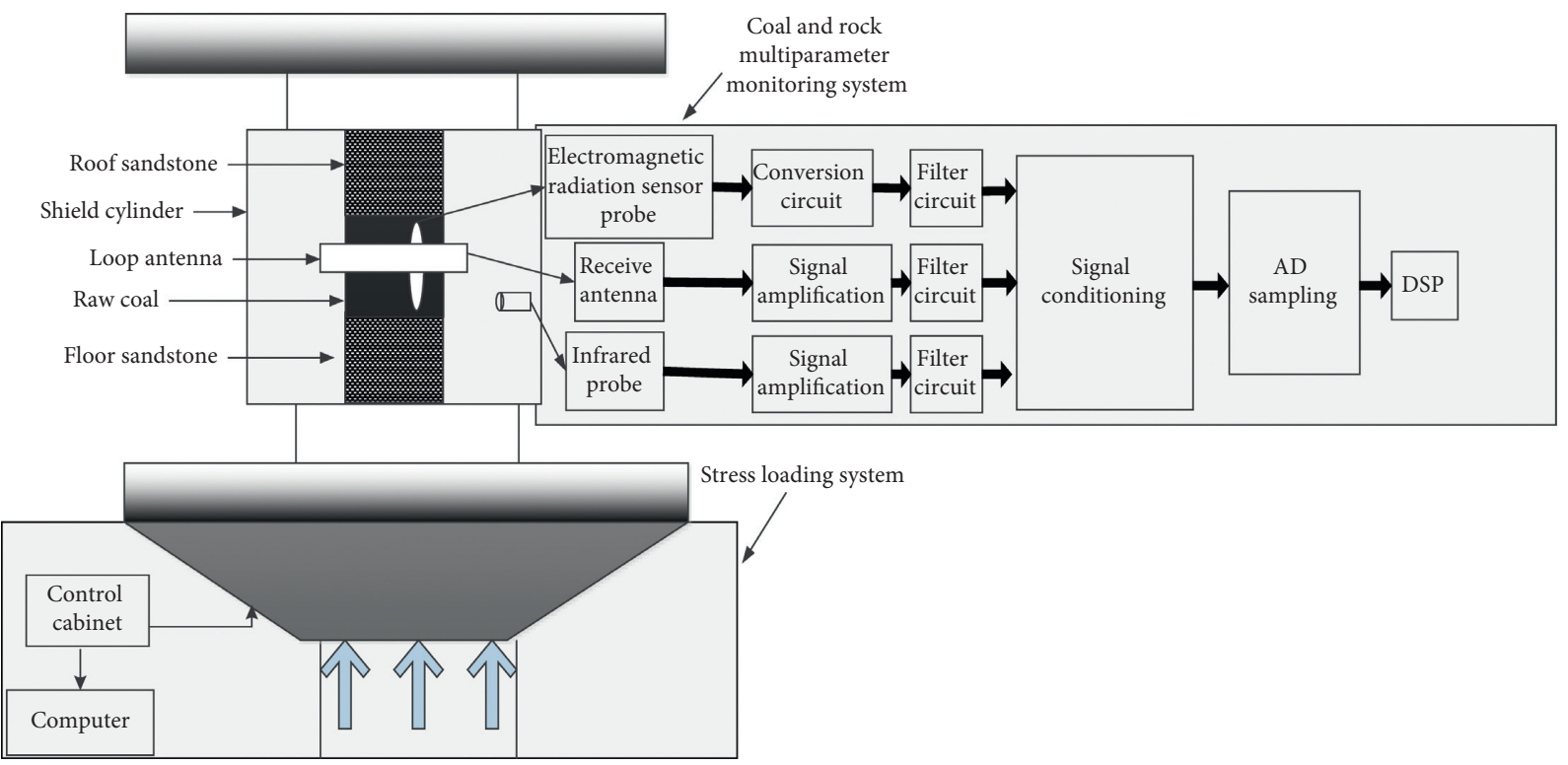

(b)

FIGURE 11: Schematic diagram of test equipment and field test. (a) Schematic diagram of field test. (b) Schematic diagram of test equipment.

internal charges of the composite coal-rock move rapidly, the coal and rock body rub against each other, and the electromagnetic radiation and temperature begin to have an obvious upward trend with the increase of stress. Entering the second stage of "loading and unloading" after $140 \mathrm{~s}$, the fracture-dislocation friction and microfracture intensified, and the electromagnetic radiation reached the maximum value at the peak value of stress. After the fracture of the sample, the rate of charge movement in the composite coalrock slowed down with the decrease of stress. The temperature of composite coal-rock is obviously affected by confining pressure, and the temperature reaches the maximum rapidly after a short transition period when the confining pressure is unloaded, and then decreases 


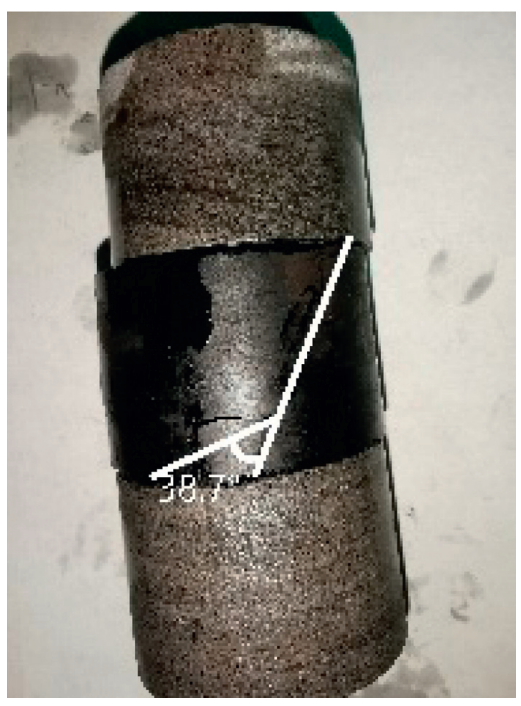

(a)

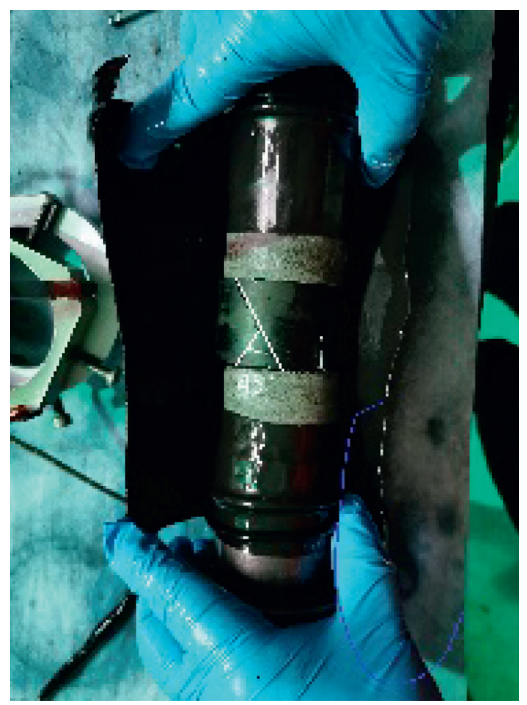

(d)

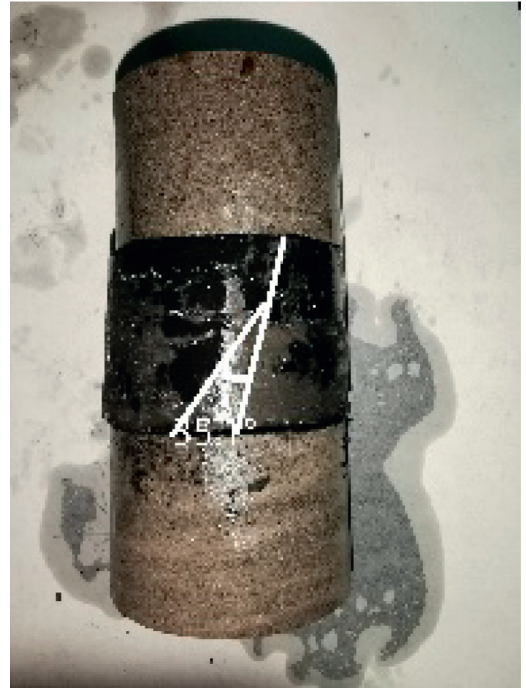

(b)

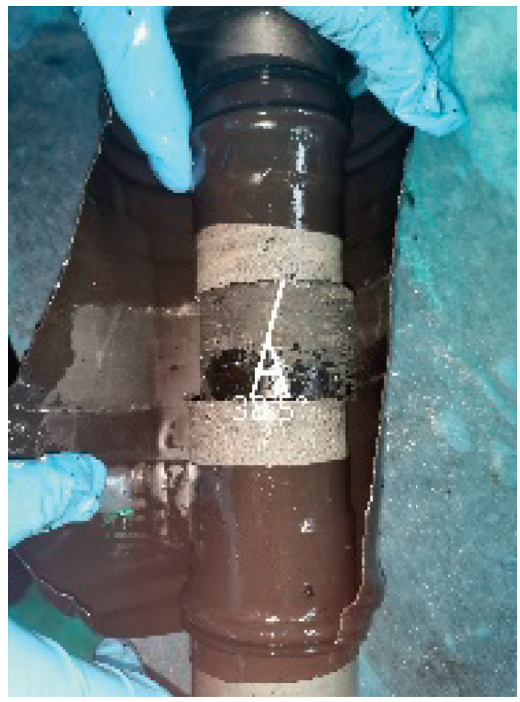

(e)

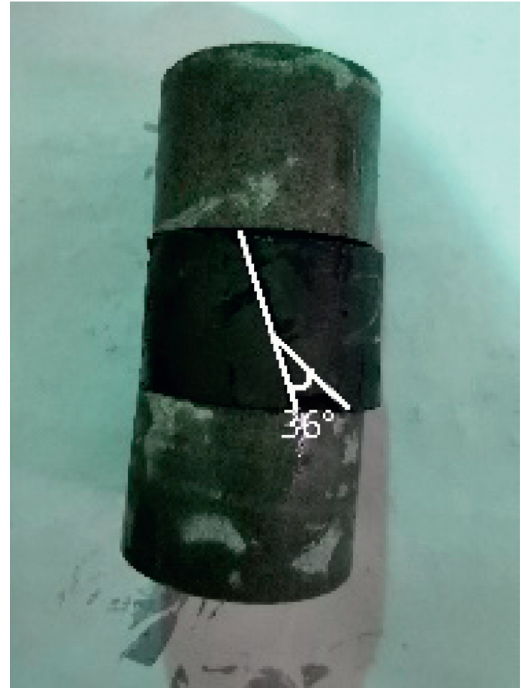

(c)

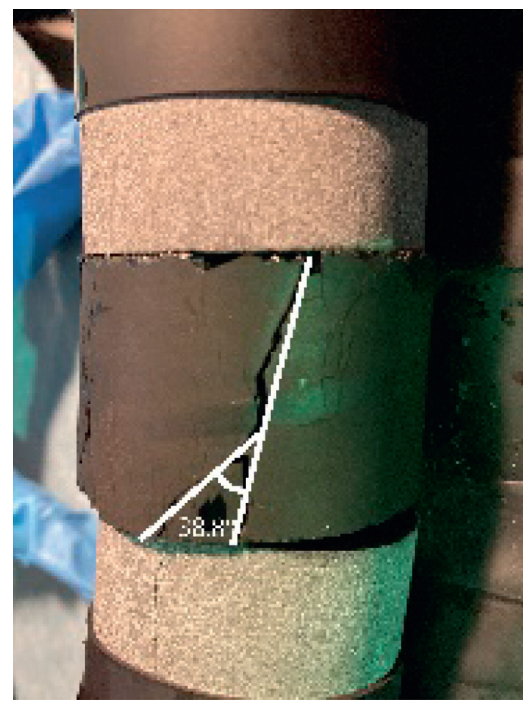

(f)

FIGURE 12: The triaxial test results of composite coal-rock samples.
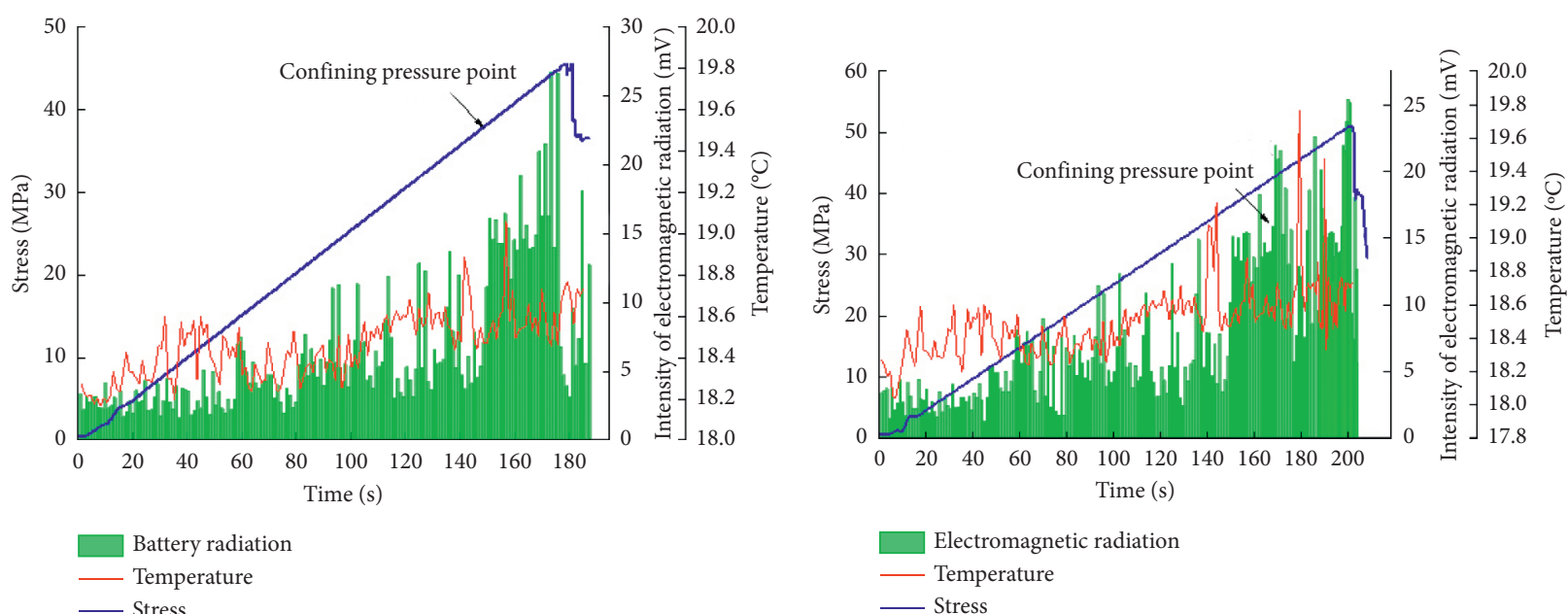

$$
\begin{aligned}
& \text { Electromagnetic radiation } \\
& \text { Temperature } \\
& \text { - Stress }
\end{aligned}
$$

(a)

(b)

FIGURE 13: (a) and (b) show the electromagnetic radiation intensity, temperature, and stress curves of the specimens unloading confining pressure at the rate of $0.05 \mathrm{MPa} / \mathrm{s}$ and $0.2 \mathrm{MPa} / \mathrm{s}$ at the same $10 \mathrm{MPa}$ confining pressure, respectively. 
gradually. The confining pressure influences the triaxial compressive strength but has no effect on the stress change trend in the whole process, and the slope of the curve has not changed. The changing trend of infrared temperature and electromagnetic radiation intensity measured by the experiment is basically consistent with the simulation results; however, there is no heat exchange between the simulation model and the outside world, so the temperature difference is larger, and the result is more ideal than the experiment, which verifies the correctness of the numerical simulation solution.

\section{Results and Discussion}

(1) In the macroscopic aspect of the loading and unloading process of composite coal-rock, many microfractures are caused by the deformation of coal and rock bodies. In the microscopic aspect, the crack extends and breaks, the intermolecular chemical bond breaks and recombines, and the variable speed movement of charge causes the change of infrared radiation and electromagnetic radiation. Based on the generalized Hooke's law and the damage mechanics formula, the mathematical model of stress field under the unloading state of composite coalrock is derived, and the multi-physical field coupling model is deduced by combining the theories of friction heat generation, piezoelectric effect, and variable speed movement of electric charge.

(2) According to the simulation results, the process of unloading confining pressure has a certain influence on the temperature field, and the composite coalrock has a short transition adaptation period at the beginning of confining pressure unloading, and the temperature rises rapidly. The change of electromagnetic field intensity of coal tends to be consistent with that of stress, and the sudden increase of electromagnetic radiation intensity reaches the peak when the stress is about to reach its peak. In the interior of the coal body, the intensity of the electromagnetic field increases gradually from the center of the coal body to the outside, the maximum value is reached at the junction with the air, and there is a small fluctuation, followed by exponential attenuation.

(3) The experimental results show that the electromagnetic radiation signal can be divided into four processes: small amplitude fluctuation, slow rise, rapid peak, and sudden drop. The infrared radiation temperature decreased at the initial stage, and there were two heating points before and after the confining pressure relief point, and the latter one was higher, and then decreased gradually. The variation trends of stress field, infrared radiation temperature field, and electromagnetic field is consistent with the simulation results.

The research results provide a theoretical basis and a new method for the effective prediction of dynamic disasters in coal and rock mining.

\section{Data Availability}

The test data used to support the findings of this study are available from the corresponding author upon request.

\section{Conflicts of Interest}

The authors declare that they have no conflicts of interest.

\section{Acknowledgments}

This work was supported by the discipline innovation team of Liaoning Technical University (grant no. LNTU20TD29), Chinese National Natural Science Foundation (grant nos. 51604141 and 51204087), and Liaoning Provincial Education Committee Projects (grant nos. LJ2019JL013 and LJ2020JCL020).

\section{References}

[1] M. Cai, "Influence of stress path on tunnel excavation response-numerical tool selection and modeling strategy," Tunnelling and Underground Space Technology, vol. 23, no. 6, pp. 618-628, 2008.

[2] V. Frid and K. Vozoff, "Electromagnetic radiation induced by mining rockfailure," International Journal of Coal Geology, vol. 64, no. 1, pp. 57-65, 2005.

[3] H. P. Xie, F. Gao, and J. Yang, "Research and development of rock mechanics in deep ground engineering," Chinese Journal of Rock Mechanics and Engineering, vol. 34, no. 11, pp. 2161-2178, 2015.

[4] Y. L. Lu, L. G. Wang, F. R. Tang, and Y. He, "Fracture evolution of overlying strata over combustion cavity under thermal-mechanical interaction during underground coal gasification," Journal of China Coal Society, vol. 37, no. 8, pp. 1292-1298, 2012.

[5] F. Gao, H. Kang, and L. Yang, "Experimental and numerical investigations on the failure processes and mechanisms of composite coal-rock specimens," Scientific Reports, vol. 10, no. 1, Article ID 13422, 2020.

[6] J. Huang, G. Xu, G. Hu, M. Kizil, and Z. Chen, "A coupled electromagnetic irradiation, heat and mass transfer model for microwave heating and its numerical simulation on coal," Fuel Processing Technology, vol. 177, pp. 237-245, 2018.

[7] X. Ding, X. C. Xiao, D. Wu, and X. F. Lv, "Mechanical properties and charge signal characteristics in coal material failure under different loading paths," International Journal of Coal Science \& Technology, vol. 1, no. 6, pp. 138-149, 2019.

[8] Z. Yang, X. P. Su, and X. Li, "Stress-charge-temperature coupling model of composite coal-rock in deformation and fracture," Journal of China Coal Society, vol. 44, no. 9, pp. 2733-2740, 2019.

[9] Z. Yang, Q. J. Qi, X. Li, and D. D. Ye, "Correlation experiments with EME signals and infrared radiation of the coalrock mixed structure in case of deformed into fractures underload," Journal of Safety and Environment, vol. 16, no. 2, pp. 103-107, 2016.

[10] Z. Yang, S. Dai, X. Li, and Q. J. Qi, “Stress-electricity-thermal coupled model of composite coal-rock indeformation and fracture under load," Journal of China Coal Society, vol. 41, no. 11, pp. 2764-2772, 2016.

[11] G. Wang, Y. S. Pan, and X. C. Xiao, "Study and application of failure characteristics and charge law of coal body under 
uniaxial loading," Rock and Soil Mechanics, vol. 40, no. 5, pp. 1823-1831, 2019.

[12] T. Yong, Z. H. Li, Z. H. Cheng et al., "Deformation and failure characteristics of composite coal mass," Environmental Earth Sciences, vol. 80, no. 3, 2021.

[13] X. K. Bao, G. Y. Guo, Y. Liu et al., "Damage characteristics and laws of micro-crack of underwater electric pulse fracturing coal-rock mass," Theoretical and Applied Fracture Mechanics, vol. 111, Article ID 102853, 2021.

[14] J. H. Li, "Study on the acoustic emission and damage characteristics of rock under different unloading rates," Mining Research and Development, vol. 38, no. 1, pp. 95-99, 2018.

[15] X. F. Liu, X. Liu, X. Wang, E. Wang, Z. Liu, and X. Xu, "Study on ultrasonic response to mechanical structure of coal under loading and unloading condition," Shock and Vibration, vol. 2017, Article ID 7643451, 12 pages, 2017.

[16] Y. X. Zhang and K. Wang, "Study on dynamic characteristics and electromagnetic signal variation characteristics of coal under," Safety in Coal Mines, vol. 50, no. 7, pp. 46-49, 2019.

[17] D. H. Ai, C. W. Li, Y. C. Zhao, and G. Y. Li, "Research on micro-seismic, electromagnetic radiation and crack propagation characteristics of coal under static loading," Rock and Soil Mechanics, vol. 41, no. 6, pp. 1-9, 2020.

[18] D. P. Shi, "Study on coal and rock damage under multiphase coupling," Scientific Journal of Intelligent Systems Research, vol. 2, no. 12, pp. 135-137, 2020.

[19] W. J. Yao, J. Y. Pang, Q. Y. Ma, and H. Lyimo, "Influence and sensitivity analysis of thermal parameters on temperature field distribution of active thermal insulated roadway in high temperature mine," International Journal of Coal Science o Technology, vol. 1, no. 8, pp. 47-63, 2021.

[20] X. P. Lai, X. M. Liu, P. F. Shan et al., "Study on thermal infrared radiation variation of fractured coal-rock mass failure during mining," Journal of Mining and Safety Engineering, vol. 36, no. 4, pp. 777-785, 2019.

[21] Y. B. Zhang, Z. Yang, X. L. Yao et al., "Experimental study on real time early warning method of roadway rockburst based on temporal and spatial evolution of infrared radiation," Journal of Mining and Safety Engineering, vol. 35, no. 2, pp. 299-330, 2018.

[22] S. D. Wang and W. Y. Hu, "Research on coal and rock mass temperature fields characteristics and control factors in deep mine," Coal Science and Technology, vol. 41, no. 8, pp. 18-21, 2013.

[23] F. Du and K. Wang, "Unstable failure of gas-bearing coal-rock combination bodies: Insights from physical experiments and numerical simulations," Process Safety and Environmental Protection, vol. 129, pp. 264-279, 2019.

[24] Y. Y. Du, H. Sun, L. Q. Ma et al., "Infrared radiation response characteristics in coal damage evolution process," Coal Science and Technology, pp. 1-9, 2021.

[25] F. Du, K. Wang, G. Wang, Y. Jiang, C. Xin, and X. Zhang, "Investigation of the acoustic emission characteristics during deformation and failure of gas-bearing coal-rock combined bodies," Journal of Loss Prevention in the Process Industries, vol. 55, pp. 253-266, 2018.

[26] Y. S. Pan, H. Luo, Z. H. Li, F. Yang, and X. C. Xiao, "Experimental study on gas permeability and charge induction of gaseous coal rock under confining pressure unloading," Chinese Journal of Rock Mechanics and Engineering, vol. 34, no. 11, pp. 713-719, 2015.

[27] Y. C. Yin and Y. Tan, Y.-w. Lu and Y.-b. Zhang, "Numerical research on energy evolution and burst behavior of unloading coal-rock composite structures," Geotechnical \& Geological Engineering, vol. 37, no. 1, pp. 295-303, 2019.

[28] Y. L. Tan and Y. B. Zhang, "Research on impact characteristics of inclined coal-rock composite body," in Proceedings of the 8th Russian-Chinese Symposium "Coal in the 21st Century: Mining, Processing, Safety”, kemerovo, Russia, October 2016.

[29] K. Wang and F. Du, "Experimental investigation on mechanical behavior and permeability evolution in coal-rock combined body under unloading conditions," Arabian Journal of Geosciences, vol. 12, no. 14, pp. 1-15, 2019.

[30] B. R. Lauen and T. R. Willshaw, Brittle Solid Fracture Mechanics, Y. Chen and Y. Xiangchu, Eds., Earthquake Press, Beijing, China, 1985.

[31] Q. S. Li, K. D. Liu, J. B. Zhu, and X. L. Lu, "Study of mechanical properties of raw coal under high stress with triaxial unloading," Chinese Journal of Rock Mechanics and Engineering, vol. 33, no. 1, pp. 24-34, 2014.

[32] W. G. Cao, M. H. Zhao, and C. X. Liu, "Study on rectified method of mohr-coulomb strength criterion for rock based on statistical damage theory," Chinese Journal of Rock Mechanics and Engineering, vol. 14, pp. 2403-2408, 2005.

[33] L. M. Zhang, Z. Q. Wang, H. Sun et al., "Failure characteristics and constitutive model of rock under unloading condition," Journal of China Coal Society, vol. 34, no. 12, pp. 1626-1631, 2009.

[34] S. Y. Chen, L. Q. Liu, P. X. Liu et al., "Theoretical and experimental study on the relationship between stress-strain and temperature response," Science in China Press, vol. 39, no. 10, pp. 1446-1455, 2009.

[35] H. F. Xiao, X. Q. He, T. Feng, and E. Y. Wang, "Research on the influence of coal and rock mechanic features on EME based on the coupling laws between EME and stress," Chinese Journal of Geotechnical Engineering, vol. 2004, no. 5, pp. 663-667, 2004.

[36] X. H. Liu, J. H. Kang, J. Yu, and Q. J. Hao, "Effect of coal-rock confining pressure based on laboratory test and numerical simulation," Journal of Water Resources and Water Engineering, vol. 31, no. 3, pp. 197-204, 2020.

[37] E. Y. Wang and X. Q. He, Electromagnetic Radiation Technology and Application in Coal and Rock, China Coal Society; China University of Mining and Technology, Beijing, China, 2007.

[38] G. Y. Hou, H. Y. Jing, J. P. Liang et al., "Experimental study on deformation and acoustic emission characteristics of rectangular roadway under different unloading rates," Rock and Soil Mechanics, vol. 40, no. 9, pp. 3309-3318, 2019.

[39] E. Z. Liu, G. X. Xie, and Y. W. Zhou, "Study on energy characteristics of concrete materials under different confining pressure unloading rates," Highway, vol. 66, no. 4, pp. 281284, 2021.

[40] S. G. Li, S. B. Liu, H. F. Lin et al., "Experimental study on deformation and failure characteristics of coal under graded cyclic loading and unloading," Coal Science and Technology, vol. 49, no. 4, pp. 1-9, 2021.

[41] Y. M. Song and X. B. Yang, "Experimental study on temperature evolution characteristics during coal failure," Rock mechanics and engineering, vol. 32, no. 7, pp. 1344-1349, 2013.

[42] X. Z. Wu, X. Gao, K. Zhao, J. W. Jian, and X. X. Liu, "Abnormality of transient infrared temperature field(ITF) in the process of rock failure," Chinese Journal of Rock Mechanics and Engineering, vol. 35, no. 8, pp. 1578-1594, 2016. 